\title{
The Inflationary Consequences of a Currency Changeover on the Catering Sector: Evidence from the Michelin Red Guide
}

\author{
Fabrizio Adriani \\ Giancarlo Marini \\ Pasquale Scaramozzino
}

Discussion Paper No. 08/604

Revised June 2008

Department of Economics

University of Bristol

8 Woodland Road

Bristol BS8 1TN 


\title{
The Inflationary Consequences of a Currency Changeover on the Catering Sector: Evidence from the Michelin Red Guide *
}

\author{
FABRIZIO ADRIANI ${ }^{\dagger}$, GIANCARLO MARINI ${ }^{\ddagger}$, and PASQUALE \\ SCARAMOZZINO $\S$ \\ ${ }^{\dagger}$ University of Bristol, and DeFiMS - SOAS - University of London \\ $\ddagger$ University of Rome "Tor Vergata" \\ $\S$ DeFiMS - SOAS - University of London, London, and University of Rome "Tor \\ Vergata"
}

June 2005, Revised: June 2008

\begin{abstract}
This paper examines the inflationary consequences of a currency changeover in the catering market. Empirical evidence from the Michelin Red Guide shows that: i) differently from restaurants in non-euro countries, restaurants in the euro area experienced abnormal price increases just after the changeover, ii) among restaurants in the euro area, tourist restaurants are responsible for most of the abnormal price increases. These results suggest that proposed explanations for the changeover effect such as menu adjustment and rounding up are only part of the story. We present a simple model of the catering market that is consistent with the evidence.
\end{abstract}

JEL-classification: D43, D82, E31, F33.

Keywords: Restaurants, Tourists, Euro, Currency Changeover.

* We thank G. Cameron, G. Corsetti, L. Deidda, D. Demery, C. Engel, N. Giammarioli, F. Giovannoni, J. Knight, A. Piergallini, F. van der Ploeg, J. Temple, F. Zilibotti and, in particular, A. Ciccone and an anonymous referee for comments and suggestions. Precious research assistance has been provided by L. Ceraso. We also thank participants to the Royal Economic Society 2004 Conference, the XXIX Simposio de Analisis Economico, the Workshop in International Economics at Tor Vergata, and seminars in Bristol and London. 


\section{Introduction}

The introduction of the Euro notes and coins on 1st January 2002 to replace national currencies has sparked off an intense debate on the economic consequences of the changeover. According to a conventional view, the change of currency should not have any effects on relative prices, since money is simply a 'veil'. The main direct consequences of the changeover should be a reduction in transaction costs, an increase in allocative efficiency due to a reduction in price uncertainty, a boost to competition due to greater price transparency.

On the other hand, a much feared cost in the public opinion, often reported by the media, was the possibility of generalized price inflation triggered by the currency changeover. Price increases in restaurants and in the service sector have indeed taken place following the introduction of the Euro. These increases have initially been attributed to the dynamics of costs in the food sector due to inclement weather conditions (European Central Bank, March 2002, April 2002). It has been argued that 'the extent of the cash changeover effect has been relatively limited, and should be temporary' (European Central Bank, July 2002).

Although price increases might have been una tantum with no long-run effect on the inflation rate, the change in relative prices may well have been permanent. This paper provides support for the layman's view that the changeover resulted in a permanent change in relative prices.

What triggered the price increases that followed the changeover? Several possible explanations have been suggested: (i) pre-existing inflation trends, (ii) increase in food costs due to bad weather, (iii) delayed and overdue adjustments of menus (Hobijin et al., 2006), and (iv) rounding-up of prices in the new currency. To these, we add a further explanation $(\mathrm{v})$ : the switch from national currencies to 
the Euro may have acted as a device that led firms to co-ordinate their expectations on pricing behaviour. The exogenous change in cash denomination has thus shifted the industry to a higher-price equilibrium. In other words, the widespread concerns about possible generalized price increases associated with the introduction of the new currency have generated self-fulfilling inflationary expectations. In this respect, the introduction of the single currency provides an interesting natural experiment. Laboratory evidence suggests that, in the presence of multiple equilibria, the nominal denomination of individuals' payoffs may determine which equilibrium is selected. Fehr and Tyran(2001) find that subjects react differently to monetary shocks depending on whether they receive payoff information in real or nominal terms. Also, Fehr and Tyran (2007) show that agents may coordinate on different equilibria when they face nominal payoffs rather than real payoffs. It is therefore interesting to assess whether the effects observed at lab level are consistent with the evidence from a natural experiment. ${ }^{1}$

We develop a simple model where customers have heterogeneous information sets. There are informed agents (locals) who know the quality of individual restaurants and uninformed agents (tourists) who do not. Restaurants choose whether to specialize in dealing only with a single type of customers or to attract both types. Low quality restaurants and restaurants located in tourist areas are more tempted to set a price that leaves negative surplus to their customers, exploiting the imperfect information of tourists. This is traded off by the cost of losing potential local customers. The model predicts that, in the presence of an upward shift of the equilibrium price, restaurants which have a comparative advantage in

\footnotetext{
${ }^{1}$ Other works make use of the natural experiment produced by the changeover to the euro. Cannon and Cipriani (2006) compare church collections before and after the Euro in Italy and Republic of Ireland. They find evidence of an increase of church giving for both countries. Another paper on donations in churches around the Euro-introduction is Soetevent (2005).
} 
attracting tourists will experience larger price increases.

The empirical part of the paper discriminates among the possible explanations by using data on individual restaurants obtained from the Michelin Red Guide. The Guide, which has the merit to provide information about restaurants according to consistent and rigorous criteria, is a rich collection of valuable data that have hitherto not been utilized for exploring the determinants of price changes over time. By looking at restaurants both inside and outside the Euro area, we can test the hypothesis that the price increases were specific to countries which experienced the changeover. By combining pre-changeover and post-changeover data, we are able to assess whether the changeover resulted in abnormal increases in prices. Finally, by exploiting the heterogeneity in the determinants of restaurants' equilibrium strategies we are able to discriminate between our model and all the competing explanations. The prediction that price increases will mainly occur in tourist locations enables us to reject explanations based on production factors, menu costs, and rounding up, that would instead apply independently of the ability to attract tourists.

It is worth noting that restaurants included by the guide are selected on the basis of the price-quality combination offered to their customers. This suggests that our results might underestimate the real impact of the changeover. Nevertheless, the evidence indicates that the changeover did trigger abnormal price increases in the euro area. As predicted by the model, tourist restaurants appear to be responsible for most of the abnormal inflation. This supports the expectation-driven view of price inflation following the changeover, against all competing alternatives. Hence, a permanent change in relative prices has occurred with the introduction of the Euro, with clear redistributional consequences. 
The plan of the paper is as follows. Section II sets up the stage for the discussion and outlines the main rationales for the price increases. Section III describes the data. Section IV presents the specification and describes the empirical results. Section V address various issues of robustness. Section VI outlines the theoretical model, which is fully derived in the Appendix. Section VII concludes.

\section{Currency changeovers and restaurant prices}

The possible explanations for higher restaurant inflation in the euro area can be grouped into explanations that are independent of the changeover and explanations that identify the changeover as the main source of price increases. Among the first group are:

i Pre-existing trends of inflation, according to which, cross-country differences in post-changeover inflation levels are the results of different inflation trends in the pre-changeover period.

ii Production factors, whereby the increase in restaurant prices is merely the result of an increase in the price of productions factors. In particular, bad weather during the changeover period might have damaged crops and increased the cost of ingredients.

Among the explanations that identify the changeover as the source of restaurant inflation are:

iii Rounding up. With the arrival of the new currency, old currency prices of all goods had to be rounded up to the nearest cent of euro. This story suggests that the rounding up might have been exploited by the sellers to increase prices. 
iv Menu adjustment. Knowing that menus had to be reprinted with the introduction of notes denominated in the new currency, restaurants delayed the update of their menus in the months preceding the changeover. According to this story, the simultaneous menu adjustment caused the price increases.

In addition to these explanations, we consider the possibility that the changeover effect may have been the result of an expectation driven shift in the equilibrium price of restaurants within the euro area. In section VI, we outline a simple model of the catering market based on imperfect information and market segmentation. The main appeal of the model is that it provides predictions which are alternative to the explanations hitherto described. We assume that restaurants attract two types of customers endowed with different information sets: regular customers who know the quality of a restaurant in advance ("locals") and all other customers ("tourists"). Restaurants differ both in the quality of their meals and in the probability to be visited by tourists. Establishments situated in more strategic locations are likely to attract more tourists than local customers. ${ }^{2}$

Our focus is on how restaurants' choice of whether to rip off or to be "honest" depends on the likelihood to be matched with uninformed consumers and on market prices. Strategic interaction between restaurants and customers may lead to a continuum of equilibrium price levels. The changeover can trigger a revision in expectations and, consequently, a change in the equilibrium prices. This could happen if, for instance, restaurants expect customers to commit mistakes when handling the new currency. ${ }^{3}$ In this case, the effect of the changeover would

\footnotetext{
${ }^{2}$ Models with informed and uninformed consumers have been widely considered in the literature. An extensive survey of the literature is beyond the scope of this paper. Among the seminal contributions are Milgrom and Roberts (1986), Bagwell and Riordan (1991), and Cooper and Ross (1984).

${ }^{3} \mathrm{An}$ informal discussion of how the changeover can alter the equilibrium is contained in section VI.
} 
be asymmetric across locations. Prices of restaurants in tourist locations would permanently increase whereas prices of restaurants in non-tourist locations would only temporarily be affected and would revert back to their normal levels. This result applies to restaurants in "extreme" locations, i.e. restaurants which have a clear comparative advantage in attracting either tourists or locals. The impact of the changeover on restaurants which are potentially attractive both for tourists and for locals is non-homogenous. Restaurants in this group might increase, keep unchanged, or even lower their prices.

As a result of the change in the equilibrium price, tourists generally face price increases. Locals could also face price increases when matched with restaurants catering for both types of customers. This helps to explain the casual evidence that many complaints about price increases actually came from locals. If faced with higher prices, locals have more readily available evidence, such as memory of past bills, to back their complaints. Thus, it is not surprising that locals were the first to start the fuss.

The fact that locals may face price increases is also consistent with the eurorelated increase in perceived inflation documented, for instance, by Dziuda and Mastrobuoni (2006).

A natural way to discriminate among the various alternatives is to consider the dynamics of the inflation differential, i.e. the difference in price change between restaurants in the euro area and restaurants outside the euro area which have not experienced the changeover. The comparison of the inflation differential before and after the changeover permits to assess the hypothesis that the "changeover effect" be just the result of different trends of inflation between euro countries and other EU countries. An increase of the inflation differential after the changeover 
would in fact reject this hypothesis. It would also cast doubts on the hypothesis that the price increases were due to an increase in the cost of production factors (e.g. ingredients), since this would likely affect euro and non euro countries alike. On the other hand, it is still possible that European regions had been affected by adverse whether conditions in an asymmetric fashion and that, due to transportation costs and other barriers to trade, the increase in the price of food had been heterogenous across Europe. Moreover, a mere analysis of the inflation differential over time would be of no help in discriminating between the rounding up hypothesis, the menu adjustment hypothesis, and the hypothesis of an expectation driven change in the equilibrium price. All these stories are compatible with an increase of the inflation differential during the changeover.

In order to identify the most likely explanation, the changeover effect must be conditioned on restaurants' individual characteristics. To this aim, we consider whether the effect of the euro varies with the potential for attracting tourists. We refer to this potential as "location". The hypotheses of menu costs, of rounding up, and of an increase in the cost of ingredients do not predict that the changeover should be conditional on location. A priori, their impact should be homogenous across tourist and non-tourist locations. By converse, the hypothesis of an expectation driven shift in the equilibrium put forward by the model suggests that restaurants in tourist locations increased their prices more than restaurants facing a clientele of locals.

\section{Data description}

We collected data from the Michelin Red Guide ("Main Cities of Europe") for six countries: Denmark, France, Germany, Italy, Sweden and UK. All the six 
countries are long-standing members of the European Union. France, Germany, and Italy have adopted the Euro as a new national currency since 2002. ${ }^{4}$ Denmark, Sweden, and UK retained their national currencies. We consider restaurants for which observations are available for all four editions. Despite euro notes having been introduced since January 2002, the 2002-2003 period is the most appropriate to capture the effect of the changeover on prices for two reasons. First, the guide is published by the end of March each year and some countries experienced a double currency regime for the first months of 2002. Second, during 2002 some local authorities kept prices under strict monitoring in order to avoid unfair rounding up. For these reasons the impact of the changeover on the 2001-2002 period should be very limited. The analysis mainly focuses on the comparison between the postchangeover period 2002-2003 and pre-changeover period 2000-2001. However, for completeness, the estimates of the inflation differential for the 2001-2002 period are also presented.

The information about restaurants' ability to attract tourists is summarized by the following dummy variables: i) TL (tourist location), which takes value 1 if the restaurant is classified as a restaurant in a tourist location and zero otherwise; ii) PL (popular location), which takes value 1 if the restaurant is in a location with no clear bias toward tourists or locals; iii) LL (local customers location), which is 1 if the restaurant is classified as a restaurant in a non-tourist location.

In order to classify restaurants, we use the description in the guide. Restaurants classified as TL must satisfy at least one of the following conditions: a)

\footnotetext{
${ }^{4}$ The events leading to the introduction of the euro can be summarized as follows. In December 1998 fixed exchange rates between euro and national currencies were announced by the national central banks of the twelve countries joining the euro. Starting from January 1999, the euro became the official currency in these countries, although no notes were issued in euros. Since January 2002 notes in national currency started to be replaced by notes in euros. The replacement process was completed on different dates across the twelve countries.
} 
restaurants for which the description explicitly states that their customers are mainly tourists, b) restaurants located in particular tourist areas, ${ }^{5}$ c) restaurants with a particular view, d) hotel restaurants. Restaurants classified as LL are: e) restaurants for which the description explicitly states that their customers are mainly regulars, f) restaurants for which the description uses expressions like "out of tourist routes" or "neighborhood restaurant" or another equivalent expression, ${ }^{6}$ g) restaurants with some rare specialty. Restaurants which either fall in both previous classes, or fall in neither of the previous classes, are classified as PL, a residual category. The motivation for conditions a), b), d), e), and f) is obvious. Why restaurants with a particular view (condition c) should be TL and restaurants with a rare specialty (condition g) should be LL is more debatable. The first criterion is consistent with the fact that panoramic areas tend to be frequented by tourists. As for the second, if a restaurant's main attraction is a special dish, then its business model probably relies on the presence of a wellinformed clientele. Customers with ex-ante information on the type of cuisine that the restaurant offers are thus more likely to go to the restaurant.

Since the guide uses a variety of expressions to describe a restaurant, whether the restaurant meets one or more of the criteria we have set is decided by a research assistant who interprets the guide's description. In section V we: a) show that our results emerge even when considering a more conservative and objective criterion to classify restaurants, b) analyze the sensitiveness of the results to alternative specification of the location variables. In particular, our results do not rely on conditions c) and $\mathrm{g}$ ).

\footnotetext{
${ }^{5}$ Whether the restaurant is in a tourist area is usually mentioned in the guide's description. Some examples: "A charming rustic atmosphere pervades this Montmartre inn...", "This historic restaurant near the Rialto...", "...was at the vanguard of Soho's culinary renaissance" (our italic).

${ }^{6}$ Some examples: "Indian restaurant in a residential street...", "Local restaurant in business district", "In an unfashionable part of town...".
} 
The procedure used to build LL, TL and PL can reasonably be assumed as exogenous in our short-term analysis. It relies on the exogenous capacity to attract tourists rather than on restaurants' short-term pricing strategies.

The guide has a measure of the perceived quality of cuisine, given by the number of stars (which takes increasing values 0,1,2,3, according to the quality). Finally, the indication of whether booking is essential can be used as a proxy of the restaurant's capacity constraints.

Relative frequencies of restaurants' characteristics are reported in table 1 . The table suggests that the euro and non-euro subsamples are very similar in terms of mix of locations and capacity constraints (BOOKING ESS.). The frequency of stars reported in the table is relative to the 2000 edition. Euro countries seem to slightly outperform non-euro countries in terms of stars awarded by the guide. UPGRADE and DOWNGRADE are binary variables which indicate whether the number of stars has respectively increased or decreased in the period considered. As the table suggests, upgrades and downgrades are relatively rare events.

As for prices, the measure of inflation is the logarithmic price change from the previous year. The guide reports a minimum and a maximum price for each restaurant. The minimum is meant to represent the price of a simple meal while the maximum is the price of an elaborate three-course meal. We present the empirical results for both prices. It is worth noting that the main results of the analysis are unchanged by the use of a midpoint price. ${ }^{7}$ The top part of table 2 reports descriptive statistics for the log change in minimum prices. Standard deviations are too high to reach any conclusion. However, it is interesting to notice that the largest gap in median inflation between euro and non euro restaurants is experienced by restaurants in tourist locations in the post-changeover periods

\footnotetext{
${ }^{7}$ Results for the midpoint price are available upon requests.
} 
$(+5.8 \%)$. Results for the maximum price go in the same direction. The largest gap between euro and non euro is experienced by restaurants in tourist locations in the pre-changeover period $(-4.2 \%)$. The sign of the difference is reversed in the post-changeover period 2002-2003 (+3.3\%).

These effects can be better grasped by looking at figures 1 and 2. For all types of locations (TL, LL, PL) they show the difference in cumulative distribution functions between euro and non euro restaurants. Figure 1 refers to the cumulative distributions for the log change in minimum price, while figure 2 performs the same analysis for the maximum price. The solid line represents the difference in the pre-changeover period 2000-2001. The dashed line is the difference in the post-changeover period 2002-2003. Negative values of the function imply that the cumulative distribution for euro restaurants lies to the right of the cumulative distribution for non-euro restaurants. The graphs are broadly consistent with a general shift to the right of the distribution for euro restaurants after the changeover, especially for the maximum price. However, for restaurants in tourist locations, the shift to the right is much more pronounced (both for maximum and minimum price). Figure 3 corroborates this intuition by looking at post-changeover differences between euro and non-euro in excess of pre-changeover differences (difference in difference). Relative to the pre-changeover situation, the euro-non-euro gap for TL (dashed line) has increased much more than the euronon-euro gap for LL (solid line). This suggests that the effect of the changeover may interact with the location of the restaurant.

Finally, the sample contains several potential outliers. For instance, in the first period (2000-2001) the top $1 \%$ of restaurants with highest change of the minimum price have experienced an increase of more than $69 \%$. The other years 
display similar extreme increases and reductions, although slightly less marked. A symptom of the effect of outliers is that, as will be discussed, robust estimates tend to differ from OLS estimates.

\section{Results}

The baseline model comprises twenty control variables. The first eighteen capture all the interactions between restaurants' locations (TL, LL, PL), period dummies (2000-01,2001-02, 2002-03), and a dummy for the euro area. The remaining control variables account for changes in price that are not related to the changeover such as a downgrade or an upgrade in the assessment of the restaurant's quality. Omitting the subscript for individual restaurants, the baseline model is:

$$
\Delta P^{j}=\alpha_{e k t}+\delta Z_{t}+\epsilon_{e k t}
$$

where $j=\min , \max ; e=$ euro, non - euro; $k=T L, P L, L L$ and $t=1,2,3$, where 1, 2, and 3 denote periods 2000-01, 2001-02, and 2002-03 respectively. $Z_{t}$ is a vector of control variables that should not interact with the changeover. Specifically, $Z_{t}$ comprises a dummy variable (UPGRADE) taking value 1 if the restaurant received an upgrade by the guide in the previous year, and a dummy variable (DOWNGRADE) taking value 1 if the restaurant received a downgrade. In the actual estimates, we slightly modify (1) to allow for a constant term. This is obtained by replacing the first period dummy for $P L$ restaurants with a constant. Since our sample contains a lower number of restaurants outside the euro area, we use a dummy taking value 1 if the restaurant is outside.

From (1), the effect of the euro on inflation is captured by the difference in difference terms. These are given by:

$$
\alpha_{\text {euro }, k, 3}-\alpha_{\text {euro }, k, 1}-\left(\alpha_{\text {non-euro }, k, 3}-\alpha_{\text {non-euro }, k, 1}\right)
$$


for $k=T L, L L, P L$.

As already mentioned, the data may present a number of outliers. For this reason we estimated the model using a robust regression approach. ${ }^{8}$ Alternative estimation methods are presented and discussed in section V. There, we also address potential problems of autocorrelation and heteroscedasticity. We believe that a robust regression approach is appropriate to the problem we consider. When outliers are not taken into account, OLS coefficients tend to be quite different depending on whether the minimum or maximum price is used. By contrast, coefficients obtained from robust regression do not suffer from this problem. Coefficients obtained with OLS also tend to be different from robust coefficients. This is generally viewed as a symptom of the presence of outliers. We interpret these results as evidence that OLS coefficients are not fully reliable.

Results for the baseline model are presented in table 3. The first eighteen control variables are the interactions between time periods, locations, and currency areas. The coefficients that should capture the differences between non-euro and euro restaurants, in the bottom half of the table, are usually either zero or negative. This suggests that inflation is generally higher for euro restaurants. As for the other control variables, only UPGRADE is significant and with the expected sign and only when the minimum price is used as dependent variable. The low frequency of upgrades and downgrades is a likely explanation for this result.

In order to assess the effect of the changeover, it is necessary to compare postchangeover differences in inflation with pre-changeover differences. This is done in table 4 where the difference in difference terms are computed. The first row

\footnotetext{
${ }^{8}$ This is implemented by using the command rreg in STATA. It works as follows. First, Cook's $\mathrm{D}$ is computed and zero weight is given to each observation for which $D>1$. Weights assigned to the other observations are based on absolute regression residuals. The procedure is iterated so that each time the regression is estimated, weights are computed, and a new regression is estimated using the new weights. Both Huber weights and biweights are used.
} 
of table 4 shows, for each type of location, differences between euro and non-euro restaurants for the pre-changeover period 2000-01. These are generally small and homogeneous across locations. The second row shows the differences after the changeover. Here the differences appear more marked in tourist locations. The difference between the second and the first row (third row) measures the impact of the changeover. The table shows that most of the changeover effect has been concentrated in tourist restaurants. For these, the estimated effect is an abnormal price increase of about $8 \%$ when the maximum price is used and about $6 \%$ when the minimum price is used. These numbers are both economically and statistically significant (1\% and $5 \%$ confidence levels respectively). For the other types, the effect is remarkably smaller and never significant.

The bottom part of table 4 presents the results obtained with a model in which restaurants' types of locations have been omitted. In other words, coefficients for all locations were constrained to be the same. The results show that the impact of the changeover is not significantly different from zero when the minimum price is used and is about $4.7 \%$ when the maximum price is used. Although the effect for the maximum price is significantly positive, an abnormal increase of $4.7 \%$ is substantially different, from an economic perspective, from the $8 \%$ increase estimated for tourist restaurants. The comparison of the two models in table 4 thus suggests that, by omitting restaurants' characteristics, one might be tempted to belittle the economic relevance of the changeover for some categories of consumers and restaurants.

Since specification (1) involves a fairly large number of control variables relative to the sample size, we also consider an alternative, more parsimonious specification. The main rationale for controlling for restaurants' characteristics is that 
the effect of the changeover is heterogenous. Therefore, a natural restriction is to assume that, in a given period, restaurants outside the euro area experienced the same level of inflation independently of their location. After all, they should not be affected by the changeover. Formally, this restriction is equivalent to assuming:

$$
\alpha_{\text {non-euro,TL,t }}=\alpha_{\text {non-euro,PL,t }}=\alpha_{\text {non-euro }, L L, t} \equiv \bar{\alpha}_{\text {non-euro, } t}
$$

where $\bar{\alpha}_{\text {non-euro,t }}$ varies through time but is constant across locations. Before estimating the restricted model, restriction (3) is tested by computing an F-test for the joint hypotheses. As will be discussed, the main results obtained with this specification are quite similar for both maximum and minimum price. However, the restriction largely passes the test when the maximum price is the dependent variable, but is not accepted when the minimum is used instead. Thus, results for the minimum price should be taken with caution.

Results are presented in table 5. The main difference between the models estimated with the maximum and with the minimum price lies in the results for the interim period 2001-02. When the maximum price is used, both restaurants classified as TL and as LL show positive coefficients already in the interim period. In principle, an increase in the differential for different types of restaurants in the interim period is compatible with a menu cost story. It is also worth noting that the guide is published at the beginning of the year and a double currency regime was in place at the beginning of 2002. This probably had the effect of limiting the price increases of euro restaurants. However, in the period 2002-03, when the double currency regime was lifted, tourist restaurants experience an unprecedented upsurge in the value of the coefficient. The fact that this is not matched by equivalent increases for other types of restaurants indicates that menu costs are only part of the story. As the table shows, this result is independent of 
whether the maximum or the minimum price is used. The difference in difference terms are presented in the top part of table 6. Although the changeover effect seems to be slightly larger when the maximum price is used ( $7 \%$ against $4.9 \%$ for the minimum price), the result in either case is the same. The changeover effect for TL is always strongly significant and is solidly larger than for other types of restaurants.

One might wonder whether the difference between TL and other types of restaurants is statistically significant. In particular, it is interesting to assess the difference between the two extreme types: TL and LL. This is illustrated in the bottom part of table 6 . The t-tests shown are for the null that the difference in difference term is the same for both TL and LL. As the table shows, the changeover effect is about $4-5 \%$ stronger for tourist restaurants and this difference is indeed statistically significant.

\section{Robustness}

In this section we test the robustness of the results discussed in the previous section. Four dimensions of robustness are of potential concern:

- robustness to the inclusion of additional restaurant characteristics,

- robustness to alternative estimation methods,

- robustness to serial correlation,

- robustness to alternative definitions for the location variables.

The first point concerns the extent to which the location dummies may capture the effect of omitted restaurant characteristics. We accordingly introduce measures of 
restaurant quality and potential capacity constraints in the analysis. The second and third points concern the estimation method. The robust regression approach we used in the previous section was motivated by the presence of outliers. Given the longitudinal nature of our data, serial correlation of residuals may be a further problem. We thus consider OLS estimates in which observations have been clustered by restaurant. The last point is motivated by the fact that the location variables are based on the interpretation of the guide's description for the restaurant. We therefore try to establish whether our main message would still hold if we were to use a more objective criterion. Finally, we discuss the possibility that the introduction of the single currency might have diverted the flows of tourists across Europe. Were this the case, our results would merely reflect a euro-driven demand shock for tourist restaurants in euro countries. For the remainder of the paper, we will omit regression outputs and only show results in a synthetic format.

\section{Robustness to additional characteristics}

The procedure we adopt consists in choosing an additional characteristic and adding to the model all the possible interactions between the selected characteristic, the time periods, and the non-euro dummy. The first characteristic considered is a dummy variable that takes value 1 if advanced booking is necessary to eat at the restaurant. This can be considered as a proxy for potential capacity constraints. Results are shown in the top part of table 7. The first row shows the difference in difference terms for restaurants for which booking is not essential. The third row shows the difference in difference term for restaurants for which booking is essential. As the table shows, BOOKING ESS. alters the effect of the changeover. Interestingly, for all types of locations, it magnifies the effect when 
the minimum price is used, and it reduces it when the maximum price is used. Although this result might appear puzzling, there is a relatively simple explanation for it. The changeover has reduced the spread (the difference between maximum and minimum price) for restaurants with capacity constraints and increased it for other restaurants. Ceteris paribus, a customer consuming a basic meal, i.e. one for which the minimum price is charged, represents a higher opportunity cost for a capacity constrained restaurant. This is because the customer is probably preventing some other customer, who in principle might be willing to spend more, from eating at the restaurant. On the other hand, if the restaurant has spare capacity, this opportunity cost is zero. This might explain why, in the presence of a coordinated increase in prices, restaurants with capacity constraints have sought to increase more the price of a basic meal whereas restaurants with spare capacity have tried to increase more the price of expensive meals. As for robustness, table 7 shows that, despite the inclusion of BOOKING ESS., the effect on tourist restaurants is always higher than the effect on other restaurants independently of whether booking is required or not. For tourist restaurants, the effect ranges from $5.7 \%$ to almost $9 \%$. In comparison, the effect for LL ranges from $2.2 \%$ to $5.3 \%$.

The second variable we consider is a proxy of quality: the number of stars awarded by the guide. In this case, considering the groups of restaurants with zero, one, two, and three stars as distinct groups is not a viable option. This would require the introduction of eighteen additional dummy variables in the baseline model. Therefore, we only separate the largest group, the restaurants with no stars, from the others. The results, showed in the bottom part of table 7 are very similar to those obtained with the introduction of BOOKING ESS. This is not surprising since the two characteristics are correlated. As before, while the vari- 
able has an effect on the impact of the changeover, the impact is still higher for restaurants in tourist locations. In summary, the inclusion of additional variables does not diminish the claim that the changeover effect mainly originates from restaurants in tourist locations.

\section{Robustness to alternative estimation methods and serial correlation}

A potential problem is the presence of serial correlation in our data. We thus verify that our results still hold if standard errors are clustered by restaurant. Since the presence of outliers could affect the OLS coefficients, we remove extreme observations. Table 8 shows the results for the OLS with clustered standard errors when 2,4 , and $6 \%$ of observations in the tails of the distribution of the dependent variable are removed. Comparing table 8 with table 4 suggests that the result that tourist restaurants are the main source of post-changeover inflation is indeed robust.

\section{Robustness to alternative definitions for the location vari- ables}

The location variables TL, LL, and PL are based on the description of the restaurant provided by the guide. Since the guide uses a variety of expressions to describe a restaurant, the construction of the variables inevitably relies on the interpretation of these expressions. We want to assess the extent to which our results are affected by the way the variables are constructed. To implement this, we take a drastic approach. Among the criteria we used to define a tourist location, there is 
one that is not susceptible of interpretation: whether the restaurant is within the premises of a hotel or not. We thus check whether there is a positive changeover effect for hotel restaurants. Results are presented in table 9. Hotel restaurants constitute only about $8 \%$ of the restaurants in our sample. Despite the limited availability of observations, table 9 shows a significant changeover effect for hotel restaurants. This ranges between $13.7 \%$ and $19.2 \%$ with robust regression (which is probably more reliable) and between $26.9 \%$ and $33.5 \%$ with OLS. ${ }^{9}$ By contrast, the changeover effect for other restaurants ranges between $1 \%$ and $4.1 \%$ with robust regression (2.9\% and $6.4 \%$ when using OLS). These results should however be taken with caution. The business strategy of an hotel restaurant is, to some extent, influenced by the strategy of the hotel. We have tried to overcome this problem by considering only establishments listed as "restaurants" in the guide and not those listed as "hotels". The formers are more likely to attract also nonresident customers. Nevertheless, we believe that a more robust assessment of the euro effect is provided by the location variables used in the previous section. The aim of this exercise is only to show that our results are not driven by arbitrary interpretations of the guide's descriptions.

We also monitor the sensitivity of the results to changes in the definitions of the location variables. In particular, two criteria deserve attention: whether the restaurant has a particular view and whether it has a rare specialty. We have considered restaurants with a particular view as TL and restaurants with a specialty as LL. These two criteria provide somewhat more ambiguous hints on the type of location than other criteria used to define TL and LL in section III. We therefore repeat the analysis by considering as PL all restaurants that either have a view

\footnotetext{
${ }^{9}$ The relatively low number of observations implies that the standard errors are quite high for hotel restaurants. This may explain why the p-values are relatively high despite the large changeover effect.
} 
or have some rare specialty and cannot be classified as TL or LL under any other criterion. The results (omitted) show that our main message is not affected by the use of a more conservative definition for TL and LL. ${ }^{10}$

\section{Euro-driven demand shocks}

We provide evidence to rule out the alternative explanation for our results namely that the introduction of the euro might have diverted tourist flows toward euro countries. Table 10 reports the percentage changes in nights spent in tourist accommodation (source: Eurostat). This is a commonly used indicator of tourist flows. The effect of the euro on tourist flows should be reflected in the number of nights spent by non-residents. The table shows no evidence of a jump of nonresidents stays for the euro countries. France and Italy roughly experienced the same growth of non-residents nights as the UK. Germany even shows a decline in the number of tourists. ${ }^{11}$ Overall rates considering both residents and nonresidents do not also differ between euro countries and non-euro countries. Hence, the hypothesis that the single currency spurred tourism in the short-term does not appear to be a likely explanation for the evidence presented.

\section{A model of the catering market}

Common explanations for the changeover effect fail to predict the heterogeneous response to the changeover by restaurants in different locations documented in the previous section. Understanding the reasons for this heterogeneity is a neces-

\footnotetext{
${ }^{10}$ Results are available upon request.

${ }^{11}$ We consider the change between nights in 2002 and nights in 2000 . This is consistent with the use of Michelin data for the 2000-2003 period since the guide is published at the beginning of the year and mostly reflects previous year prices.
} 
sary step towards the development of policy recommendations for countries which might, in the future, adopt the common currency. This section presents a simple model of the catering market whose predictions match the observed behaviour of restaurants. Here, we outline the crucial assumptions and the main predictions. A formal discussion is contained in the Appendix.

The set of players is formed by customers and (monopolistic) restaurants. The (exogenously determined) quality of a restaurant can be either high or low. We treat restaurant meals as 'experience' goods (Nelson, 1970; Cooper and Ross, 1984). ${ }^{12}$ There are two types of customers: informed (locals) and uninformed (tourists). Locals always know in advance the quality of a given restaurant whereas tourists only learn it after the meal. However, tourists observe the price charged by the restaurant and other characteristics such as its location, and coherently update their beliefs.

We refer to the uninformed customers as 'tourists'. This should not be taken literally. The model and its empirical implications would not change if we allowed a fraction of the actual tourist population to acquire information through tourist guides or by talking to the locals. What is relevant is that a fraction of the tourists is typically uninformed, as suggested by casual observation. When we use the word 'tourists', we imply this fraction. By the same token, the data on quality employed in the empirical analysis, which are taken from a tourist guide, are assumed to form a richer information set than the one available to the (uninformed) tourists.

\footnotetext{
${ }^{12}$ Chan and Leland (1982) consider the problem of 'search goods' (i.e. those goods whose quality can only be observed after bearing some information cost). Real world goods usually fall in between these two categories. Despite tourists being able to obtain some information on the quality of a restaurant, for instance by purchasing a tourist guide, the restaurant example resembles more the case of an experience good (von Ungern-Sternberg and von Weizsacker, 1985).
} 
Restaurants and customers are randomly matched. The probability for restaurant $i$ to be matched with a tourist ('location') varies across restaurants. Prior to the matching stage, restaurants post a price for the meal (which we assume to be a take it or leave it offer). Hence, restaurants are not able to discriminate between locals and tourists. A possible interpretation of these assumptions is that every restaurant is required to display a menu before knowing whether the match will be with a tourist or with a local and is committed to the prices shown in the menu.

Restaurants choose between three business models: i) charging a price that attracts both types of customers, ii) charging a price that attracts only tourists, iii) charging a price that attracts only locals. Each restaurant chooses its particular business model according to its location and its quality. Restaurants in tourist locations profit relatively more from attracting tourists. At the same time, low quality restaurants can profit, if matched with a tourist, from mimicking high quality restaurants. Hence, they have a higher incentive to deal with tourists. Proposition 1 in the Appendix establishes that whenever the production cost of a high quality meal is low enough, there is a continuum of equilibria. ${ }^{13}$ These equilibria can be characterized as follows: i) restaurants in non-tourist locations tend to charge the locals' reservation price thereby extracting all the surplus from their customers, ii) low quality restaurants in tourist locations charge a price $p^{T}$ and attract only tourists (who experience negative surplus), iii) high quality restaurants in tourist locations also charge $p^{T}$ attracting both types of customers (who obtain positive surplus).

The type of equilibrium selected, and the associated equilibrium price, depend

\footnotetext{
${ }^{13}$ We focus on pure strategy Perfect Bayesian Equilibria. In order to obtain sharp empirical predictions, we restrict attention to equilibria in which all trade between restaurants and tourists occurs at the same price, $p^{T}$.
} 
on agents' beliefs about the price that will prevail. A simultaneous and coordinated revision of beliefs about the price at which tourists will trade may thus trigger a price shift from an equilibrium to another one. However, a change in the equilibrium would never affect the price of those restaurants which find it optimal to deal only with locals in both the initial and the final equilibrium. Their customers would never accept a price higher than their reservation price and the restaurants have no incentive to lower their price. A change in the equilibrium may only affect prices set by restaurants whose clientele, in either equilibrium, comprises a positive fraction of tourists. As proposition 2 shows, if the price $p^{T}$ prevailing in equilibrium experiences an upward shift, the location determines the effect on the price of a particular restaurant. In particular, restaurants whose probability to be matched with a tourist exceeds a given threshold will (weakly) increase their prices, while restaurants with probability below a certain threshold will not change their prices. The intuition is that restaurants with a low probability to attract tourists are more likely to be visited by locals who can exert a more informed control on the price/quality combination they offer. By contrast, restaurants with a high probability of capturing tourists face fewer locals and are therefore more willing to take advantage from the change in $p^{T}$.

How might the changeover have provoked such a change? An example is formally analyzed in the appendix. Here, we informally discuss the main intuitions. Suppose that the static game described so far were repeated a number of times. A new generation of tourists enters the economy at the beginning of each period and leaves at the end of the period. We assume that agents are aware of prevailing prices in the previous periods and, except for the period in which the changeover occurs, always play equilibrium strategies. During this interim period, customers 
could commit mistakes due to the change in cash denomination. This is a standard assumption in models dealing with the inflationary effects of the changeover - see for instance Dziuda and Mastrobuoni (2006) and Lippi and Gaiotti (2004). This idea is also supported by empirical evidence. Dziuda and Mastrobuoni (2006) report that, during the changeover, individuals had difficulties in dealing with the new currency. In particular, they tended to think in terms of old currencies, felt that they could benefit from double pricing, and had problems in comparing prices.

Since mistakes are the results of the difficulties of handling a new currency, we assume that they affect the behaviour of both tourists and locals in the same fashion. ${ }^{14}$ In particular, when matched with a restaurant, customers are likely to accept offers at prices different from the one they would have accepted before the changeover, provided that the difference is relatively small. As the new price moves away from the previous level, the likelihood that the offer is accepted declines. Since mistakes are relatively more costly for restaurants which usually deal with a number of customers than for individual agents, we assume that restaurants make accurate calculations and do not commit mistakes when announcing their prices.

If a restaurant catering only for locals tries to exploit the changeover by increasing its price in the interim period, it will be forced to revert back to the previous level the following period, since its customers would desert it otherwise. By contrast, if a restaurant catering for tourists charges a higher price, there is no reason why it should revert to the pre-changeover price the following period, when mistakes disappear. This is a result of the indeterminacy of the price at which

\footnotetext{
${ }^{14}$ This is a conservative assumption. If prices were more transparent to regular customers as it is fair to assume - our predictions would still hold. For instance, Dziuda and Mastrobuoni (2006) consider a model where the transparency of prices in the new currency is endogenous and find that transparency is negatively related to changeover-driven inflation.
} 
tourists trade: there is a continuum of equilibrium values for $p^{T}$. In the working paper version, we argue that it is possible to conceive of reasonable off-equilibrium beliefs that force a temporary increase of the price at which tourists trade to be-

come permanent. As a consequence, while customers' mistakes influence the behaviour of restaurants for locals only temporarily, they may permanently alter the equilibrium behaviour of restaurants catering for tourists or for both tourists and locals. This happens even though the mistakes themselves are only temporary.

\section{Conclusions}

The introduction of the euro has had inflationary consequences on the service sector and in particular on the catering market. Restaurant prices have registered marked increases in the euro zone. The evidence from the Michelin Red Guide suggests that: i) abnormal price increases in the euro area immediately after the changeover were not matched by similar increases outside the euro area, ii) most of the 'changeover effect' came from restaurants catering for tourists. The first result confirms that the abnormal price increases were not driven by a shock common to all European countries. They were specific to countries in the Euro area. Within these countries, the marked price increases in restaurants in tourist locations would seem to indicate that suggested justifications in terms of rounding-off of prices in the new currency or overdue and delayed adjustment of menus can at best only be part of the story.

There has been a speculative change in relative prices in Euroland, with redistributional effects in favour of the catering sector. 


\section{References}

Bagwell. K. and Riordan, M.H. (1991). 'High and declining prices signal product quality', American Economic Review, Vol. 81, pp. 224-239.

European Central Bank (2002). Monthly Bulletin, March, April, and July, ECB, Frankfurt.

Cannon, E.S. and Cipriani, G.P. (2006). 'Euro-illusion: a natural experiment', Journal of Money, Credit, and Banking, Vol. 38, pp. 1391-1403.

Chan, Y. and Leland, H. (1982). 'Prices and qualities in markets with costly information', Review of Economic Studies, Vol. 49, pp. 499-516.

Cho, I.K. and Kreps, D.M. (1987). 'Signaling games and stable equilibria', Quarterly Journal of Economics, Vol. 102, pp. 179-221.

Cooper, R. and Ross, T.W., (1984). 'Prices, product qualities and asymmetric information: The competitive case', Review of Economic Studies, Vol. 51, pp. 197-207.

Dziuda, W. and Mastrobuoni, G. (2006). 'The euro changeover and its effects on price transparency and inflation', Working Paper, Collegio Carlo Alberto.

Fehr, E. and Tyran, J.T. (2001). 'Does money illusion matter?', American Economic Review, Vol. 91, pp. 1239-1262.

Fehr, E. and Tyran, J.T. (2007). 'Money illusion and coordination failures', Games and Economic Behavior, Vol. 58, pp. 246-268.

Gaiotti, E. and Lippi, F. (2004). 'Pricing behavior and the introduction of the euro: Evidence from a panel of restaurants in Italy', Giornale degli Economisti, Vol. 63, pp. 491-526.

Hobijn, B., Tambalotti, A. and Ravenna, F. (2006). 'Menu costs at work: Restaurant prices and the introduction of the euro', Quarterly Journal of Eco- 
nomics, Vol. 121, pp. 1103-1131.

Milgrom, P. and Roberts, J. (1986). 'Price and advertising signals of product quality'. Journal of Political Economy, Vol. 94, pp. 796-821.

Michelin Guide (2000, 2001, 2002, 2003). The Red Guide: Main Cities of Europe, Michelin Travel Publications, Watford, UK.

Nelson, P. (1970). 'Information and consumer behavior', Journal of Political Economy, Vol. 78, pp. 311-329.

Soetevent, A.R. (2005). 'Anonymity in giving in a natural context: a field experiment in 30 churches', Journal of Public Economics, Vol. 89, pp. 2301-2323.

Von Ungern-Sternberg, T. and von Weizsacker, C.C. (1985). 'The supply of quality on a market for "experience goods" '. Journal of Industrial Economics, Vol. 33, pp. 531-540.

\section{Appendix A: The model}

There is a large number, formally a continuum, of restaurants in the economy. Conditional on being matched with a customer, restaurant $i$ has an exogenous probability $\lambda_{i} \in[0,1]$ to be matched with a tourist, where $\lambda_{i}$ has a continuous distribution $\mathcal{F}:[0,1] \rightarrow[0,1]$ with full support. For simplicity we refer to $\lambda_{i}$ as "location". In general, $\lambda_{i}$ is a measure of the restaurant's ability to attract tourists. Restaurant $i$ has a probability $1-\lambda_{i}$ to be matched with a local. For a large number of matches, $\lambda_{i}$ and $1-\lambda_{i}$ can be interpreted as the fractions of tourists and locals in the total clientele. We assume that the restaurant's location, $\lambda_{i}$, is observable by everyone.

It is worth noting that the introduction of stochastic matching implies that restaurants do not compete. This assumption appears especially reasonable in 
the catering sector which is usually characterised by spatial dispersion, capacity constraints, and barriers related to the free entry of new firms in the presence of equilibrium profits.

In addition to being different in the probability to be spotted by tourists, restaurants also differ in their quality. There are high quality, $h$, and low quality, $l$, restaurants. The set of restaurants is given by $\Omega=\{l, h\} \times[0,1]$. For any $\lambda_{i}$, there is a fraction $\mu^{x}$ of type- $x$ restaurants, where $\mu^{x} \in[0,1], x \in\{l, h\}$, $\mu^{l}+\mu^{h}=1$. Producing meals is costly and the unit cost depends on quality: $c(l)<c(h)$.

Customers (locals/tourists) have inelastic demand and consume either one meal or nothing. We assume that customers obtain 0 in the case they do not accept the offer of the restaurant. Both customer-types want to maximise their surplus:

$$
U(x)=v(x)-p
$$

where $p$ is price and $v(x)$ is the utility associated with a meal of quality $x \in\{l, h\}$. We assume that $c(h)>v(l)$. Accordingly, under perfect information, no customer would ever buy from a restaurant of low quality at any price that is also feasible for a high quality restaurant.

\section{Restaurants' business models}

Locals solve a trivial problem. Whenever $v(x) \geq p$ they accept the offer. Tourists must compute expectations given the observable characteristics of the restaurant. Upon observing restaurant $i$ with location $\lambda_{i}$, charging price $p_{i}$, the expected payoff for a tourist is $E\left(v\left(x_{i}\right) \mid p_{i}, \lambda_{i}\right)-p_{i}$ when accepting the offer and 0 when declining it. 
The notion of equilibrium in this model reduces to a Perfect Bayesian Equilibrium in the (signaling) game in which restaurants choose their prices and customers decide whether to accept or to decline the offers.

Definition 1. A (pure strategy) Perfect Bayesian Equilibrium is a profile of restaurant prices, a profile of strategies (accept, decline) for customers, and a set of beliefs for tourists such that: i) restaurants optimally choose their prices on the basis of their ability to attract tourists $\left(\lambda_{i}\right)$, their quality, and customers' strategies; ii) tourists' beliefs, upon observing $\lambda_{i}$ and $p_{i}$, are derived from restaurants' strategies using Bayes rule where possible; iii) customers' strategies are optimal given their beliefs.

For empirical convenience, we restrict attention to Perfect Bayesian Equilibria in which all trade between restaurants and tourists occurs at a unique price, $p^{T}$. Such equilibria can always be sustained by postulating that tourists, upon observing an off-equilibrium price, assume that the quality of the restaurant announcing that price is relatively low. ${ }^{15}$

Restaurants must decide among three alternative business models: dealing with both locals and tourists, dealing only with tourists, and dealing only with locals. The restaurants associated with the three models are respectively denoted as Popular Restaurants (PR), Restaurants for Tourists (RT) and Restaurants for Regulars (RR).

A tourist suffers an ex-post loss when he goes to a Restaurant for Tourists. If he were not, then locals would also go to the RT. But then the restaurant would no longer be a RT. A RT would then charge $p^{T}$, where $p^{T}>v\left(x_{i}\right)$. Notice also that for the tourist not to be able to detect the rip-off, there must be restaurants with an equivalent location and quality higher than $p^{T}$ for which it is optimal to charge $p^{T}$.

\footnotetext{
${ }^{15}$ Other equilibria may be possible if, for example, we allow restaurants with different locations to trade with tourists at different prices. Considering these equilibria would complicate the analysis withour adding to the intuition.
} 
A RR charges a price that is different from $p^{T}$ and is not higher than the utility associated with its expected quality. These restaurants are able to extract all the consumers' surplus since their customers (locals) know their quality, and RR know they know. Hence, in equilibrium, $\mathrm{RR}$ always charge $p_{i}=v\left(x_{i}\right)$. Tourists can actually recognize RR since these restaurants charge prices different from $p^{T}$ in equilibrium. However, zero surplus implies that it is (weakly) optimal for tourists to reject the offers of RR.

Finally, a PR charges $p^{T} \leq v\left(x_{i}\right)$. In this way, it will attract both types of customers. Note that customers obtain non-negative surplus when matched with a popular restaurant.

Profits associated with each business model are:

$$
\begin{gathered}
\Pi_{P R}=p^{T}-c\left(x_{i}\right) ; \quad p^{T} \leq v\left(x_{i}\right) \\
\Pi_{R T}=\lambda_{i}\left(p^{T}-c\left(x_{i}\right)\right) ; p^{T}>v\left(x_{i}\right) \\
\Pi_{R R}=\left(1-\lambda_{i}\right)\left(v\left(x_{i}\right)-c\left(x_{i}\right)\right) ; v\left(x_{i}\right) \neq p^{T}
\end{gathered}
$$

The incentive to deal with tourists depends on the price $p^{T}$ prevailing in the market and on the ability to attract them, $\lambda_{i}$. Restaurants with a high $\lambda_{i}$ will always choose to deal with tourists provided that $p^{T}$ be high enough. If $p^{T}$ is higher than the utility associated with their quality they will become RT. Otherwise, they will opt for becoming PR. Symmetrically, the incentive to deal only with locals is stronger for restaurants with a low $\lambda_{i}$. 


\section{Equilibrium analysis}

The set of equilibria we analyse is characterised by a distribution of prices such that $\mathrm{PR}$ and RT announce $p_{i}=p^{T}$, while $\mathrm{RR}$ announce $p_{i}=v\left(x_{i}\right)$.

First note that there always exists an equilibrium, characterised by $p^{T}=v(l)$, in which only low quality restaurants deal with tourists (PR) and high quality restaurants only cater for locals (RR). This is a typical situation $\grave{a}$ la Akerlof where higher qualities are driven out of the tourist segment of the market.

Equilibria other than the one characterised by $p^{T}=v(l)$ require that $p^{T}>c(h)$. If $p^{T}$ were lower than or equal to $c(h)$, no high quality restaurant would charge $p^{T}$ and tourists would make a certain loss when trading at $p^{T}$. Given $p^{T}>c(h)$, low quality restaurants decide whether to charge $v(l)$ and be $\mathrm{RR}$ or charge $p^{T}$ and be RT. High quality restaurants choose between charging $v(h)$ and being RR, and charging $p^{T}$ and being PR. The following result establishes conditions for the existence of equilibria other than the one characterised by $p^{T}=v(l)$.

\section{Proposition 1. If}

$$
\frac{\mu^{h} v(h)+\mu^{l} v(l)}{\mu^{h}+\mu^{l}}>c(h)
$$

then there exist a continuum of equilibria characterised by a tourist price $p^{T}$ in the interval

$$
\left[c(h), \frac{\mu^{h} v(h)+\mu^{l} v(l)}{\mu^{h}+\mu^{l}}\right]
$$

Note that $c(h)$ is the minimum price that a restaurant of quality $h$ can charge without incurring a loss. The expression on the left hand side of inequality (8) is the expected utility from trading at $p^{T}$ given the tourist's posterior beliefs. In these equilibria, tourists experience a positive surplus when matched with a high quality restaurant and a negative surplus when matched with low quality restaurants. ${ }^{16}$

\footnotetext{
${ }^{16}$ Even though the equilibria we analyse are characterised by a certain degree of pooling of
} 
If restaurants believe that tourists will trade at a particular value of $p^{T}$, they will charge that value. This implies that if beliefs are revised, the economy could shift to an equilibrium with different prices. The following proposition suggests that there is a testable relationship between the price change of a restaurant and its location:

Proposition 2. Assume that a revision of beliefs selects an equilibrium characterised by a higher tourist price $p^{T}$. Then, there exist $\lambda^{*}$ and $\tilde{\lambda}<\lambda^{*}$ such that: i) every restaurant, $i$, with $\lambda_{i} \geq \lambda^{*}$, charges a price greater than or equal to its initial price; ii) every restaurant $\lambda_{i}<\tilde{\lambda}$ leaves its price unchanged.

As explained in the proof, restaurants in less "extreme" locations (i.e. $\lambda_{i} \in$ $\left.\left[\tilde{\lambda}, \lambda^{*}\right)\right)$ raise or lower their prices according to their quality.

\section{Changeover, mistakes, and shifts in equilibrium prices: an example}

After having analysed the effect of a change in the equilibrium, we turn to the issue of how the changeover might have provoked such a change. A possible example (tough not the only one) is the following. Suppose that the static game we described so far was repeated a finite number of times. In each period, a new generation of tourists enter the economy and leave at the end of the period. We assume that in all periods all agents play equilibrium strategies, except for period $t$ in which the changeover occurs. In the interim period $t$, we allow for the possibility that customers commit mistakes due to the change in cash denomination. Mistakes are the results of the difficulties of handling a new currency and, therefore, affect the behaviour of tourists as well as locals. However, we shall different types of restaurants, the beliefs supporting these equilibria are robust to the Intuitive Criterion (Cho and Kreps, 1987). Low quality restaurants could always benefit from deviating to a higher price if tourists, upon observing the deviation from the equilibrium, were to believe that the restaurants deviating were, for instance, high quality restaurants. Therefore, beliefs assigning a low quality upon observing a deviation from the equilibrium are robust. 
argue below, while customers' mistakes influence the behaviour of restaurants for locals only temporarily, they may permanently alter the equilibrium behaviour of restaurants catering for tourists or for both. We consider the following sort of mistakes. A customer (tourist/local) who, if present in period $t-1$, would have been willing to accept the offer of restaurant $i$ charging ${ }_{t-1} p_{i}$, accepts the offer at any price ${ }_{t} p_{i}={ }_{t-1} p_{i}+\Delta$ with probability $m(\Delta) \in[0,1]$ if matched with restaurant $i$ in period $t . m($.$) is assumed to be continuous and differentiable.$ The function has a global maximum at $\Delta=0$, with $m^{\prime}(\Delta) \geq 0$ for $\Delta<0$ and $m^{\prime}(\Delta) \leq 0$ for any $\Delta>0 .{ }^{17}$ We also assume that $m(\Delta)$ goes to zero fairly quickly as $|\Delta|$ increases. The intuition is that customers are more likely to accept the offers at prices that are relatively closer to the pre-changeover equilibrium price for restaurant $i{ }_{t-1} p_{i}$. As the new price moves away from ${ }_{t-1} p_{i}$, the likelihood that the offer is accepted never increases. Although for simplicity we have not explicitly introduced competition among restaurants into the model, the probability $m(\Delta)$ may be interpreted as a reduced form that should capture the effect of competitive pressures. Finally, we assume that types of customers who would not have accepted the offer at ${ }_{t-1} p_{i}$, keep doing so and reject any offer in the neighborhood of ${ }_{t-1} p_{i}$.

Since mistakes are relatively more costly for restaurants which usually deal with a number of customers, we assume that restaurants make accurate calculations and do not commit mistakes when announcing their prices. Given the customers' behaviour, restaurant $i$ in period $t$ solves:

$$
\max _{\Delta} m(\Delta)\left[{ }_{t-1} p_{i}+\Delta-c\left(x_{i}\right)\right]
$$

\footnotetext{
${ }^{17}$ Results would not change if we assumed that the probability $m(\Delta)$ decrease only when the price increases $(\Delta>0)$ and remain constant when the price decreases or remains constant $(\Delta \leq 0)$.
} 
From the first order condition, the optimal $\Delta$ for restaurant $i\left(\Delta_{i}\right)$ solves ${ }_{t-1} p_{i}+$ $\Delta_{i}=c\left(x_{i}\right)-\frac{m\left(\Delta_{i}\right)}{m^{\prime}\left(\Delta_{i}\right)}$. This, given ${ }_{t-1} p_{i}+\Delta_{i} \geq c\left(x_{i}\right)$, implies $\Delta_{i}>0$. Note also that $\Delta_{i}$ depends on restaurant $i$ 's quality, $x_{i}$, so that type $h$ restaurants experience different price increases from type $l$.

Since $\Delta_{i}>0$ for all restaurants, all restaurants will raise their prices in period t. However, an essential difference between restaurants catering only for locals and all other restaurants arises in period $t+1$ when mistakes disappear and equilibrium play is resumed. If restaurant $i$ only caters for locals, it is forced to revert to ${ }_{t+1} p_{i}={ }_{t-1} p_{i}=v\left(x_{i}\right)$ (provided it keeps catering only for locals in period $t+1$ ), since the locals would desert it otherwise. By converse, restaurants which cater only for tourists or for both announce ${ }_{t-1} p_{i}=p^{T}$ in period $t-1$, and ${ }_{t} p_{i}=p^{T}+\Delta_{i}$ in period $t$. However, there is no reason why the price should revert to $p^{T}$ in period $t+1$. In fact, a different equilibrium price $\tilde{p}^{T}$ may arise. What price will be selected depends on how tourists' beliefs out of the equilibrium path are affected by the changeover.

We now illustrate how changes in off-equilibrium beliefs may lead to a permanent increase in the equilibrium price $\tilde{p}^{T}$. Suppose that, at $t+1$, tourists trade at the new equilibrium price $\tilde{p}^{T}$. Upon observing an off-equilibrium price $p$ at $t+1$, tourists hold the following beliefs. If $p$ is identical to some price posted at time $t$, they conjecture that the quality associated with $p$ reflects the quality that used to be sold at $p$ at $t$. In other words, tourists would assume that the restaurant has just "forgotten" to charge the new equilibrium price. Let $p^{T}+\bar{\Delta}, \bar{\Delta}>0$, be the price charged at time $t$ by the high quality restaurants that were dealing with tourists. Our off-equilibrium beliefs imply that if tourists observe $p^{T}+\bar{\Delta}$ at time $t+1$, they conjecture that the restaurant is of type $h$. Hence, provided that $\bar{\Delta}$ is 
not too large, they will accept to consume at the restaurant. As a result, $\tilde{p}^{T}$ must exceed $p^{T}+\bar{\Delta}$. Otherwise, no type of restaurant ( $h$ or $l$ ) would ever charge $\tilde{p}^{T}$, since they can charge $p^{T}+\bar{\Delta}$. The changeover has thus provoked a positive shift in the equilibrium price at which tourists trade.

\section{Proofs}

\section{Proof of Proposition 1}

Tourists will accept the offer of a restaurant charging $p^{T}$ if $E\left(v\left(x_{i}\right) \mid p^{T}, \lambda_{i}\right) \geq$ $p^{T}$. We first establish that if $p^{T}$ is in the interval described in Proposition 1 , there is a positive fraction of restaurants of type $l$ and $h$ which charge $p^{T}$. Then, we prove that it is optimal to trade at $p^{T}$ for tourists. From equations (5) and (7), high quality restaurants will choose to charge $p^{T}$ and behave as PR (rather than charging $v(h)$ and behave as RR) if their probability $\lambda_{i}$ is above the threshold:

$$
\lambda(h) \equiv \frac{v(h)-p^{T}}{v(h)-c(h)}
$$

By construction, $\lambda(h)<1$ whenever $p^{T}>c(h)$. Hence, at any price above $c(h)$ there are type $h$ restaurants for which charging $p^{T}$ is optimal given tourists' offequilibrium beliefs. From equations (6) and (7), type $l$ restaurants prefer to be RT (rather than RR) if their $\lambda_{i}$ is above:

$$
\lambda(l) \equiv \frac{v(l)-c(l)}{p^{T}+v(l)-2 c(l)}
$$

where $\lambda(l)$ is strictly less than $1 / 2$ whenever $p^{T}>v(l)$. This always occurs in the interval $\left[c(h), \frac{\mu^{h} v(h)+\mu^{l} v(l)}{\mu^{m}+\mu^{l}}\right]$, since $c(h)>v(l)$. Hence, there are always restaurants of type $l$ willing to charge $p^{T}$. As for tourists, note that, whenever $\lambda(h)>\lambda(l)$, type $l$ restaurants with $\lambda(l) \leq \lambda_{i}<\lambda(h)$ could not profit from charging $p^{T}$ as long as tourist are able to observe their location. The reason is that it is suboptimal to 
charge $p^{T}$ for all high quality restaurants with $\lambda_{i}<\lambda(h)$. Hence, if $\lambda(h)>\lambda_{i} \geq$ $\lambda(l)$, the tourist would assume, upon observing a restaurant $\lambda_{i}$ charging $p^{T}$, that he is facing a low quality restaurant. If so, knowing that a tourist would never accept their offers, these restaurants will instead charge $v(l)$ and deal with locals only. Hence, $\lambda_{i} \geq \lambda(l)$ is necessary but not sufficient for a low quality restaurant to charge $p^{T}$. Symmetrically, if $\lambda(l)>\lambda_{i} \geq \lambda(h)$, the tourist would correctly detect a high quality restaurant and would always accept the offer. Thus, the tourist is actually uncertain about the quality only when $\lambda_{i} \geq \max [\lambda(h), \lambda(l)]$. Since both $\lambda(l)$ and $\lambda(h)$ are less than 1 when $p^{T} \in\left[c(h), \frac{\mu^{h} v(h)+\mu^{l} v(l)}{\mu^{m}+\mu^{l}}\right]$, there are always restaurants whose quality cannot be assessed with certainty. In these cases, the posterior belief of the tourist is that the restaurant is low quality with probability $\mu^{l} /\left(\mu^{h}+\mu^{l}\right)$ and high quality with probability $\mu^{h} /\left(\mu^{h}+\mu^{l}\right)$. Therefore, the expected utility will be:

$$
E\left(v\left(x_{i}\right) \mid p^{T}, \lambda_{i}\right)=\frac{\mu^{h} v(h)+\mu^{l} v(l)}{\mu^{h}+\mu^{l}}
$$

which is the maximum price the tourist is willing to pay and, therefore, the upper bound for $p^{T}$.

\section{Proof of Proposition 2}

As in Proposition 1, low quality restaurants decide whether to be RR or RT. Let $\lambda(l)$ denote the threshold value of $\lambda_{i}$ that determines the choice of the business model for type $l$ restaurants. $\lambda(l)$ follows from (6) and (7):

$$
\lambda(l) \equiv \frac{v(l)-c(l)}{p^{T}+v(l)-2 c(l)}
$$


From equations (5) and (7), high quality restaurants find it optimal to charge $p^{T}$ if their $\lambda_{i}$ is above:

$$
\lambda(h) \equiv \frac{v(h)-p^{T}}{v(h)-c(h)}
$$

We have already noted that, for a type $l$ restaurant, the condition $\lambda_{i} \geq \lambda(l)$ is only necessary for charging $p^{T} . \quad \lambda_{i} \geq \lambda(h)$ should also hold, otherwise the tourists would be able to assess that these restaurants are not high quality by observing their location. We denote with a " $*$ " the values of variables in the initial equilibrium and with a " " the values in the final equilibrium. Since $\lambda(l)$ and $\lambda(h)$ are decreasing in $p^{T}$, for $\tilde{p}^{T}>p^{* T}$, the relationships $\tilde{\lambda}(l)<\lambda^{*}(l)$ and $\tilde{\lambda}(h)<\lambda^{*}(h)$ must hold. Consider now all restaurants such that $\lambda_{i} \geq \lambda^{*}(h)$. All high quality restaurants with $\lambda_{i} \geq \lambda^{*}(h)$ were charging $p^{* T}$ in the initial equilibrium and therefore charge $\tilde{p}^{T}$ in the final equilibrium. Thus, they have raised their price. Within low quality restaurants with $\lambda_{i} \geq \lambda^{*}(h)$, a positive fraction $\left(1-\mathcal{F}\left(\max \left[\lambda^{*}(l), \lambda^{*}(h)\right]\right)\right)$ were charging $p^{* T}$, and a (possibly zero) fraction $\left(\max \left[\mathcal{F}\left(\lambda^{*}(l)\right)-\mathcal{F}\left(\lambda^{*}(h)\right), 0\right]\right)$ were charging $v(l)$ in the initial equilibrium. In the final equilibrium, all the restaurants in the first group and, provided $\lambda^{*}(l)>\lambda^{*}(h)$, a fraction $\mathcal{F}\left(\lambda^{*}(l)\right)-\mathcal{F}\left(\max \left[\tilde{\lambda}(l), \lambda^{*}(h)\right]\right)$ of restaurants in the second group switch to $\tilde{p}^{T}$, thus increasing their prices. The rest keeps charging $v(l)$. Thus, they have either raised their price or left it unchanged. But then, defining $\lambda^{*} \equiv \lambda^{*}(h)$ proves point i). Consider now restaurants with $\lambda_{i}<\tilde{\lambda}(h)$. Since $\tilde{\lambda}(h)<\lambda^{*}(h)$ high quality restaurants were charging $v(h)$ in the initial equilibrium and keep doing so in the final equilibrium. At the same time, low quality restaurants were also charging $v(l)$ in the initial equilibrium and, because of their location, cannot credibly pretend to be high quality by announcing $\tilde{p}^{T}$. Thus, they keep announcing $v(l)$. Therefore, defining $\tilde{\lambda} \equiv \tilde{\lambda}(h)$ proves point ii). Finally, we give 
account of the the behaviour of restaurants in the interval $\left[\tilde{\lambda}, \lambda^{*}\right)$. In this case, the price change is conditional on the restaurant's quality. High quality restaurants were initially charging $v(h)$ and now charge $\tilde{p}^{T}$ thus reducing their price. Low quality restaurants were also charging the locals' reservation price in the initial equilibrium. In the final equilibrium, they either charge $\tilde{p}^{T}$ (which is higher) or stick to the locals' reservation price. 
TABLE 1: Relative frequencies of restaurants' characteristics

\begin{tabular}{cccc}
\hline & All Sample & Euro & Non-Euro \\
\hline Obs. per period & 661 & 496 & 165 \\
TL & $32 \%$ & $33 \%$ & $27 \%$ \\
LL & $44 \%$ & $46 \%$ & $39 \%$ \\
PL & $24 \%$ & $21 \%$ & $34 \%$ \\
HOTEL & $8 \%$ & $8 \%$ & $7 \%$ \\
(Hotel Restaurant) & & & \\
BOOKING ESS. & $25 \%$ & $27 \%$ & $22 \%$ \\
& & & \\
NO STARS & $72 \%$ & $67 \%$ & $85 \%$ \\
ONE STAR & $17 \%$ & $20 \%$ & $12 \%$ \\
TWO STARS & $8 \%$ & $10 \%$ & $2 \%$ \\
THREE STARS & $3 \%$ & $3 \%$ & $1 \%$ \\
& & & \\
UPGRADE & & & \\
2000-2001 & $1.8 \%$ & $1.8 \%$ & $1.8 \%$ \\
2001-2002 & $1.5 \%$ & $1.8 \%$ & $0.6 \%$ \\
2002-2003 & $1.2 \%$ & $1.4 \%$ & $0.6 \%$ \\
DOWNGRADE & & & \\
2000-2001 & $0.6 \%$ & $0.8 \%$ & $0.0 \%$ \\
2001-2002 & $2.1 \%$ & $2.4 \%$ & $1.2 \%$ \\
2002-2003 & $1.4 \%$ & $1.8 \%$ & $0.0 \%$ \\
& & & \\
\hline
\end{tabular}

Notes: TL is a dummy variable taking value 1 if the restaurant is in a tourist location. LL is a dummy variable taking value 1 if the restaurant is in a location for local costumers. PL is a dummy variable taking value 1 if the restaurant is neither in a tourist location nor in a local costumers' location. HOTEL is a dummy variable taking value 1 if the restaurant is within the premises of an hotel. BOOKING ESSENTIAL is a dummy variable taking value 1 if the guide recommends advance booking. The number of stars awarded to a restaurant is an indicator of the quality of its cuisine. UPGRADE (DOWNGRADE) is a dummy variable taking value 1 if the number of stars granted to the restaurant by the guide has increased (decreased) in the period considered. The Euro subsample includes restaurants in France, Germany, and Italy. The Non-Euro subsample includes restaurants in Denmark, Sweden, and UK. 
TABLE 2: Descriptive statistics of restaurant inflation

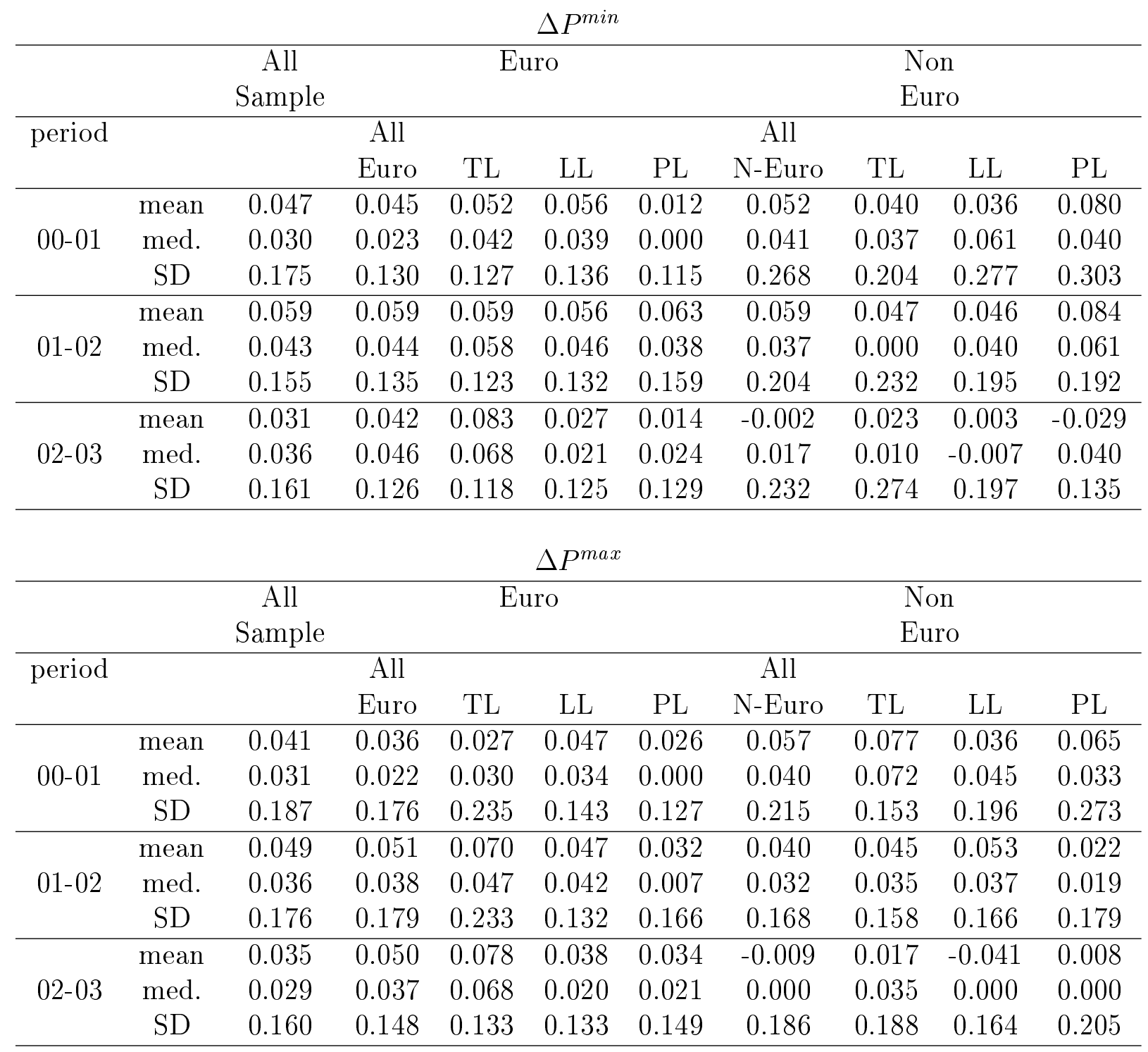

Notes: $\Delta P^{\text {min }}$ is the log-change of the minimum price relative to the previous year edition for the period considered. $\Delta P^{\max }$ is the log-change of the maximum price relative to the previous year edition. 
TABLE 3: Robust estimates of restaurant inflation

\begin{tabular}{ccccccc}
\hline & & & \multicolumn{3}{c}{ Dependent } & \multicolumn{2}{c}{ Variable } \\
Period $\times$ & Location $\times$ & Non Euro & $\Delta P^{\text {min }}$ & \multicolumn{2}{c}{$\Delta P^{\text {max }}$} \\
Dummy & Dummy & Dummy & Coeff. & S.E. & Coeff. & S. E. \\
\hline$/$ & $/$ & NO & 0.015 & 0.011 & 0.014 & 0.011 \\
$2000-2001$ & TL & NO & $0.031^{*}$ & 0.015 & $0.031^{*}$ & 0.015 \\
$2000-2001$ & LL & NO & $0.029^{*}$ & 0.014 & $0.027^{*}$ & 0.014 \\
$2001-2002$ & $/$ & NO & 0.027 & 0.016 & -0.003 & 0.016 \\
$2001-2002$ & TL & NO & 0.013 & 0.015 & $0.039^{* *}$ & 0.015 \\
$2001-2002$ & LL & NO & 0.012 & 0.014 & $0.035^{*}$ & 0.014 \\
$2002-2003$ & $/$ & NO & 0.009 & 0.016 & 0.016 & 0.016 \\
$2002-2003$ & TL & NO & $0.051^{* * *}$ & 0.015 & $0.044^{* *}$ & 0.015 \\
$2002-2003$ & LL & NO & 0.001 & 0.014 & 0.000 & 0.014 \\
$/$ & $/$ & YES & 0.010 & 0.019 & 0.024 & 0.019 \\
$2000-2001$ & TL & YES & -0.011 & 0.028 & 0.004 & 0.027 \\
$2000-2001$ & LL & YES & -0.003 & 0.025 & -0.019 & 0.025 \\
$2001-2002$ & $/$ & YES & 0.009 & 0.027 & -0.006 & 0.027 \\
$2001-2002$ & TL & YES & $-0.079^{* *}$ & 0.028 & -0.016 & 0.027 \\
$2001-2002$ & LL & YES & -0.024 & 0.025 & -0.032 & 0.025 \\
$2002-2003$ & $/$ & YES & 0.021 & 0.027 & -0.037 & 0.027 \\
$2002-2003$ & TL & YES & $-0.094^{* * *}$ & 0.028 & -0.039 & 0.027 \\
$2002-2003$ & LL & YES & $-0.061^{*}$ & 0.025 & -0.018 & 0.025 \\
\hline UPGRADE & & Other Control Variables & & & \\
DOWNGRADE & & & $0.052^{*}$ & 0.022 & 0.029 & 0.022 \\
\hline Obs & & & 0.021 & 0.023 & -0.022 & 0.023 \\
\hline F-Test & & & 1983 & & 1983 & \\
\hline & & & $3.30^{* * *}$ & & $2.60 * * *$ & \\
\hline
\end{tabular}

Notes: The table presents robust regression results. The dependent variable is the log-change in minimum (maximum) price relative to the previous year edition. The first eighteen explanatory variables are given by the interactions between time periods (2000-2001, 2001-2002, 2002-2003), locations (TL, LL, PL), and Euro/Non Euro areas. UPGRADE (DOWNGRADE) is a dummy variable taking value 1 if the number of stars granted to the restaurant by the guide has increased (decreased) in the period considered. The model is:

$$
\begin{aligned}
& \Delta P=\beta_{0}+\beta_{9} D_{N E}+\left(\beta_{1}+\beta_{10} D_{N E}\right) D_{00-01} \times T L+\left(\beta_{2}+\beta_{11} D_{N E}\right) D_{00-01} \times L L+ \\
& +\left(\beta_{3}+\beta_{12} D_{N E}\right) D_{01-02}+\left(\beta_{4}+\beta_{13} D_{N E}\right) D_{01-02} \times T L+\left(\beta_{5}+\beta_{14} D_{N E}\right) D_{01-02} \times L L+ \\
& +\left(\beta_{6}+\beta_{15} D_{N E}\right) D_{02-03}+\left(\beta_{7}+\beta_{16} D_{N E}\right) D_{02-03} \times T L+\left(\beta_{8}+\beta_{17} D_{N E}\right) D_{02-03} \times L L+ \\
& +\beta_{18} U P G R A D E+\beta_{19} D O W N G R A D E
\end{aligned}
$$

$D_{N E}$ is the non euro dummy. $D_{(t-1)-t}$ are period dummies. ${ }^{*}=5 \%$ significant ${ }^{* *}=1 \%$ significant. ${ }^{* * *}=0.1 \%$ significant. 
TABLE 4: Differences in inflation between euro and non-euro countries before and after the changeover

\begin{tabular}{|c|c|c|c|c|c|c|c|}
\hline \multicolumn{2}{|l|}{$\begin{array}{c}\text { Unrestricted } \\
\text { Model }\end{array}$} & \multicolumn{3}{|c|}{$\Delta P^{\min }$} & \multicolumn{3}{|c|}{$\Delta P^{\max }$} \\
\hline Location & & TL & LL & $\mathrm{PL}$ & $\mathrm{TL}$ & LL & $\mathrm{PL}$ \\
\hline diff before & (a) & 0.000 & -0.008 & -0.010 & -0.028 & -0.005 & -0.024 \\
\hline diff after & (b) & 0.062 & 0.029 & -0.032 & 0.053 & 0.031 & 0.014 \\
\hline $\begin{array}{c}\text { diff in diff } \\
\text { t-test }\end{array}$ & $(b)-(a)$ & 0.062 & 0.037 & -0.021 & 0.081 & 0.036 & 0.037 \\
\hline$(b)-(a)=0$ & & $2.218^{*}$ & 1.575 & -0.781 & $2.909^{* *}$ & 1.559 & 1.371 \\
\hline p-value & & 0.027 & 0.115 & 0.436 & 0.004 & 0.119 & 0.170 \\
\hline $\begin{array}{l}\text { Restricted } \\
\text { Model I }\end{array}$ & & & $\Delta P^{\min }$ & & & $\Delta P^{\max }$ & \\
\hline diff before & (a) & & -0.003 & & & -0.015 & \\
\hline diff after & (b) & & 0.019 & & & 0.032 & \\
\hline $\begin{array}{c}\text { diff in diff } \\
\text { t-test }\end{array}$ & $(b)-(a)$ & & 0.022 & & & 0.047 & \\
\hline$(b)-(a)=0$ & & & 1.487 & & & $3.191^{* *}$ & \\
\hline $\mathrm{p}$-value & & & 0.137 & & & 0.001 & \\
\hline
\end{tabular}

Notes: The unrestricted model is the model estimated in table 3. Diff before is the price change for euro restaurants minus the price change for non-euro restaurants in period 2000-2001. Diff after is the price change for euro restaurants minus the price change for non-euro restaurants in period 2002-2003. For TL, diff before is $-\left(\beta_{9}+\beta_{10}\right)$, diff after is $-\left(\beta_{9}+\beta_{15}+\beta_{16}\right)$. For LL, diff before is $-\left(\beta_{9}+\beta_{11}\right)$, diff after is $-\left(\beta_{9}+\beta_{15}+\beta_{17}\right)$. For PL, diff before is $-\beta_{9}$, diff after is $-\left(\beta_{9}+\beta_{15}\right)$. See table 3 for the coefficients.

The restricted model (regression output omitted) is:

$$
\begin{array}{r}
\Delta P=\beta_{0}+\beta_{3} D_{N E}+\left(\beta_{1}+\beta_{4} D_{N E}\right) D_{01-02}+\left(\beta_{2}+\beta_{5} D_{N E}\right) D_{02-03}+ \\
+\beta_{6} U P G R A D E+\beta_{7} D O W N G R A D E
\end{array}
$$

See table 3 for the description of the variables. Diff before is $-\beta_{3}$. Diff after is $-\left(\beta_{3}+\beta_{5}\right)$. $*=5 \%$ significant ${ }^{* *}=1 \%$ significant. ${ }^{* * *}=0.1 \%$ significant. 
TABLE 5: Robust estimates of restaurant inflation (restricted model II)

\begin{tabular}{|c|c|c|c|c|c|c|}
\hline \multirow{3}{*}{$\begin{array}{c}\text { Period } \times \\
\text { Dummy }\end{array}$} & \multirow{3}{*}{$\begin{array}{l}\text { Location } \times \\
\text { Dummy }\end{array}$} & \multirow{3}{*}{$\begin{array}{c}\text { Euro } \\
\text { Dummy }\end{array}$} & \multicolumn{4}{|c|}{ Dependent Variable } \\
\hline & & & \multicolumn{2}{|c|}{$\Delta P^{\min }$} & \multicolumn{2}{|c|}{$\Delta P^{\max }$} \\
\hline & & & Coeff. & S.E. & Coeff. & S. E. \\
\hline 1 & / & $\mathrm{NO}$ & $0.042^{* * *}$ & 0.009 & $0.051^{* * *}$ & 0.009 \\
\hline 2001-2002 & / & $\mathrm{NO}$ & -0.002 & 0.013 & -0.015 & 0.013 \\
\hline 2002-2003 & / & $\mathrm{NO}$ & -0.020 & 0.013 & $0.040^{* *}$ & 0.013 \\
\hline / & / & YES & -0.027 & 0.015 & $-0.037^{*}$ & 0.014 \\
\hline 2000-2001 & TL & YES & $0.031^{*}$ & 0.015 & $0.030 *$ & 0.014 \\
\hline $2000-2001$ & LL & YES & $0.030^{*}$ & 0.014 & $0.027^{*}$ & 0.014 \\
\hline 2001-2002 & / & YES & 0.029 & 0.021 & 0.012 & 0.020 \\
\hline 2001-2002 & TL & YES & 0.013 & 0.015 & $0.039 * *$ & 0.015 \\
\hline 2001-2002 & LL & YES & 0.012 & 0.014 & $0.035^{* *}$ & 0.014 \\
\hline 2002-2003 & / & YES & 0.029 & 0.021 & $0.056^{* *}$ & 0.020 \\
\hline 2002-2003 & TL & YES & $0.051^{* * *}$ & 0.015 & $0.044^{* *}$ & 0.014 \\
\hline 2002-2003 & LL & YES & 0.001 & 0.014 & 0.000 & 0.014 \\
\hline \multicolumn{7}{|c|}{ Other Control Variables } \\
\hline UPGRADE & & & $0.050^{*}$ & 0.022 & 0.029 & 0.021 \\
\hline DOWNGRADE & & & 0.022 & 0.023 & -0.022 & 0.023 \\
\hline Obs & & & 1983 & & 1983 & \\
\hline$\%$ weight $=0$ & & & $2.0 \%$ & & $1.9 \%$ & \\
\hline F-Test & & & $3.32^{* * *}$ & & $3.49^{* * *}$ & \\
\hline
\end{tabular}

Notes: The table presents estimates of a restricted model in which different locations (TL, LL, PL) have different coefficients only if the restaurant is in the euro area. The dependent variable is log-change in minimum (maximum) price relative to the previous year edition. The model estimated is:

$$
\begin{aligned}
& \Delta P=\gamma_{0}+\gamma_{1} D_{01-02}+\gamma_{2} D_{02-03}+\gamma_{3} D_{E}+\gamma_{4} D_{00-01} \times T L \times D_{E}+\gamma_{5} D_{00-01} \times L L \times D_{E}+ \\
& \quad+\gamma_{6} D_{01-02} \times D_{E}++\gamma_{7} D_{01-02} \times T L \times D_{E}+\gamma_{8} D_{01-02} \times L L \times D_{E}+\gamma_{9} D_{02-03} \times D_{E}+ \\
& +\gamma_{10} D_{02-03} \times T L \times D_{E}+\gamma_{11} D_{02-03} \times L L \times D_{E}+\gamma_{12} U P G R A D E+\gamma_{13} D O W N G R A D E
\end{aligned}
$$

where $D_{E}$ is the euro dummy. ${ }^{*}=5 \%$ significant ${ }^{* *}=1 \%$ significant. ${ }^{* * *}=0.1 \%$ significant. 
TABLE 6: Differences in inflation between euro and non-euro countries before and after the changeover (restricted model II)

\begin{tabular}{cccccccc}
\hline $\begin{array}{c}\text { Restricted } \\
\text { Model II }\end{array}$ & \multicolumn{3}{c}{$\Delta P^{\text {min }}$} & & \multicolumn{3}{c}{$\Delta P^{\text {max }}$} \\
\hline Location & & TL & LL & PL & TL & LL & PL \\
diff before & $(a)$ & 0.004 & 0.003 & -0.027 & -0.006 & -0.010 & -0.037 \\
diff after & $(b)$ & 0.053 & 0.003 & 0.002 & 0.063 & 0.019 & 0.019 \\
diff in diff & $(b)-(a)$ & 0.049 & 0.000 & 0.029 & 0.070 & 0.029 & 0.056 \\
t-test & & & & & & & \\
$(b)-(a)=0$ & & $2.700^{* *}$ & 0.020 & 1.390 & $3.86^{* * *}$ & 1.73 & $2.75^{* *}$ \\
p-value & 0.007 & 0.982 & 0.164 & 0.000 & 0.084 & 0.006 \\
& & & & & & & \\
\hline
\end{tabular}

Comparison between TL and LL

\begin{tabular}{cccc}
\hline $\operatorname{diff}_{T L}-\operatorname{diff}_{L L}$ & & $\Delta P^{\text {min }}$ & $\Delta P^{\text {max }}$ \\
\hline before & $(c)$ & 0.001 & 0.003 \\
after & $(d)$ & 0.050 & 0.044 \\
& $(d)-(c)$ & 0.049 & 0.041 \\
t-test & & & \\
$(d)$ - $(c)=0$ & & $2.880^{* *}$ & $2.420^{*}$ \\
p-value & & 0.004 & 0.016 \\
\hline
\end{tabular}

Notes: Restricted model II is the model estimated in table 5. Diff before is the price change for euro restaurants minus the price change for non-euro restaurants in period 2000-2001. Diff after is the price change for euro restaurants minus the price change for non-euro restaurants in period 2002-2003. For TL, diff before is $\gamma_{3}+\gamma_{4}$, diff after is $\gamma_{3}+\gamma_{9}+\gamma_{10}$. For LL, diff before is $\gamma_{3}+\gamma_{5}$, diff after is $\gamma_{3}+\gamma_{9}+\gamma_{11}$. For PL, diff before is $\gamma_{3}$, diff after is $\gamma_{3}+\gamma_{9}$. See table 5 for the coefficients.

The bottom part of the table compares the inflation differential (euro minus non-euro) for TL with that of LL. The first term $(c)$ is $\gamma_{4}-\gamma_{5}$. The second term $(d)$ is $\gamma_{10}-\gamma_{11}$. The third term, $(d)-(c)$, is $\gamma_{10}-\gamma_{11}-\left(\gamma_{4}-\gamma_{5}\right)$. ${ }^{*}=5 \%$ significant $* *=1 \%$ significant. $* * *=0.1 \%$ significant. 
TABLE 7: Differences in inflation between euro and non-euro countries before and after the changeover: robustness to additional restaurants' characteristics

\begin{tabular}{|c|c|c|c|c|c|c|c|}
\hline $\begin{array}{c}\text { Booking } \\
\text { Essential }\end{array}$ & & \multicolumn{3}{|c|}{$\Delta P^{\min }$} & \multicolumn{3}{|c|}{$\Delta P^{\max }$} \\
\hline & Location & TL & LL & $\mathrm{PL}$ & TL & LL & $\mathrm{PL}$ \\
\hline $\mathrm{NO}$ & diff in diff & 0.057 & 0.031 & -0.027 & 0.089 & 0.042 & 0.040 \\
\hline \multirow{3}{*}{ YES } & t-test & 1.920 & 1.250 & -0.970 & $3.010^{* *}$ & 1.700 & 1.430 \\
\hline & diff in diff & 0.079 & 0.053 & -0.005 & 0.069 & 0.022 & 0.020 \\
\hline & t-test & $2.110^{*}$ & 1.510 & -0.130 & 1.840 & 0.630 & 0.520 \\
\hline $\begin{array}{c}\text { Number of } \\
\text { stars } \geq 1\end{array}$ & & & $\Delta P^{\min }$ & & & $\Delta P^{\max }$ & \\
\hline \multirow[t]{2}{*}{$\mathrm{NO}$} & diff in diff & 0.048 & 0.022 & -0.027 & 0.087 & 0.048 & 0.043 \\
\hline & t-test & 1.650 & 0.920 & -1.000 & $3.020^{* *}$ & $1.980^{*}$ & 1.590 \\
\hline \multirow[t]{2}{*}{ YES } & diff in diff & 0.091 & 0.066 & 0.016 & 0.032 & -0.007 & -0.011 \\
\hline & t-test & $2.180^{*}$ & 1.670 & 0.370 & 0.770 & -0.180 & -0.260 \\
\hline
\end{tabular}

Notes: The results reported in the table refer to robust regressions in which additional characteristics and their interactions with time periods and currency areas have been alternatively added to the base model (see table 3 ). The additional characteristics considered are whether booking is essential and whether the restaurant has been awarded 1 or more stars. Diff in diff is the difference between euro restaurants and non-euro restaurants in the period 2002-03 minus the difference between euro restaurants and non-euro restaurants in the period $2000-01 .^{*}=5 \%$ significant ${ }^{* *}=1 \%$ significant. ${ }^{* * *}=0.1 \%$ significant. 
TABLE 8: Differences in inflation: OLS with $x \%$ of observations in tails removed and S.E. clustered by restaurant.

\begin{tabular}{|c|c|c|c|c|c|c|c|}
\hline $\begin{array}{c}2 \% \text { of obs. } \\
\text { removed }\end{array}$ & & & $\Delta P^{\min }$ & & & $\Delta P^{\max }$ & \\
\hline Location & & TL & $\overline{\mathrm{LL}}$ & $\overline{\mathrm{PL}}$ & TL & $\overline{\mathrm{LL}}$ & $\mathrm{PL}$ \\
\hline diff before & $(a)$ & -0.010 & 0.012 & 0.001 & -0.046 & 0.004 & -0.004 \\
\hline diff after & $(b)$ & 0.042 & 0.009 & -0.006 & 0.083 & 0.066 & -0.001 \\
\hline $\begin{array}{c}\text { diff in diff } \\
\text { t-test }\end{array}$ & $(b)-(a)$ & 0.052 & -0.003 & -0.008 & 0.128 & 0.061 & 0.003 \\
\hline$(b)-(a)=0$ & & 1.61 & -0.08 & -0.21 & $3.16^{* *}$ & 1.820 & 0.090 \\
\hline p-value & & 0.107 & 0.937 & 0.830 & 0.002 & 0.069 & 0.932 \\
\hline $\begin{array}{c}4 \% \text { of obs. } \\
\text { removed }\end{array}$ & & & $\Delta P^{\min }$ & & & $\Delta P^{\max }$ & \\
\hline Location & & TL & LL & $\mathrm{PL}$ & TL & LL & $\mathrm{PL}$ \\
\hline diff before & (a) & -0.013 & -0.009 & -0.013 & -0.033 & 0.014 & -0.014 \\
\hline diff after & $(b)$ & 0.058 & 0.013 & -0.028 & 0.069 & 0.060 & -0.003 \\
\hline $\begin{array}{c}\text { diff in diff } \\
\text { t-test }\end{array}$ & $(b)-(a)$ & 0.070 & 0.022 & -0.015 & 0.102 & 0.047 & 0.011 \\
\hline$(b)-(a)=0$ & & $2.35 *$ & 0.73 & -0.51 & $2.66^{* *}$ & 1.62 & 0.32 \\
\hline p-value & & 0.019 & 0.468 & 0.611 & 0.008 & 0.107 & 0.751 \\
\hline $\begin{array}{c}6 \% \text { of obs. } \\
\text { removed }\end{array}$ & & & $\Delta P^{\text {min }}$ & & & $\Delta P^{\max }$ & \\
\hline diff before & $(a)$ & -0.010 & -0.002 & -0.013 & -0.022 & -0.001 & 0.003 \\
\hline diff after & $(b)$ & 0.052 & 0.020 & -0.034 & 0.075 & 0.062 & -0.004 \\
\hline $\begin{array}{c}\text { diff in diff } \\
\text { t-test }\end{array}$ & $(b)-(a)$ & 0.062 & 0.022 & -0.022 & 0.098 & 0.063 & -0.007 \\
\hline$(b)-(a)=0$ & & $2.11^{*}$ & 0.84 & -0.85 & $2.72^{* *}$ & $2.20 *$ & -0.200 \\
\hline $\mathrm{p}$-value & & 0.035 & 0.403 & 0.395 & 0.007 & 0.028 & 0.841 \\
\hline
\end{tabular}

Notes: The model estimated is identical to the model presented in table 3 (regression output is omitted). Diff before is the price change for euro restaurants minus the price change for non-euro restaurants in period 2000-2001. Diff after is the price change for euro restaurants minus the price change for non-euro restaurants in period 2002-2003. For TL, diff before is $-\left(\beta_{9}+\beta_{10}\right)$, diff after is $-\left(\beta_{9}+\beta_{15}+\beta_{16}\right)$. For LL, diff before is $-\left(\beta_{9}+\beta_{11}\right)$, diff after is $-\left(\beta_{9}+\beta_{15}+\beta_{17}\right)$. For PL, diff before is $-\beta_{9}$, diff after is $-\left(\beta_{9}+\beta_{15}\right)$. See table 3 for the coefficients. ${ }^{*}=5 \%$ significant ${ }^{* *}=1 \%$ significant. ${ }^{* * *}=0.1 \%$ significant. 
TABLE 9: Differences in inflation between euro and non-euro countries before and after the changeover: hotel restaurants vs other restaurants

\begin{tabular}{|c|c|c|c|c|c|}
\hline $\begin{array}{c}\text { Robust } \\
\text { Regression }\end{array}$ & & $\Delta P^{\min }$ & & & $\Delta P^{\max }$ \\
\hline Hotel Restaurant & & YES & $\mathrm{NO}$ & YES & $\mathrm{NO}$ \\
\hline diff before & (a) & -0.098 & 0.003 & -0.065 & -0.012 \\
\hline diff after & $(b)$ & 0.094 & 0.012 & 0.071 & 0.029 \\
\hline $\begin{array}{c}\text { diff in diff } \\
\text { t-test }\end{array}$ & $(b)-(a)$ & 0.192 & 0.009 & 0.137 & 0.041 \\
\hline$(b)-(a)=0$ & & $3.52^{* * *}$ & 0.61 & $2.51^{*}$ & $2.65^{* *}$ \\
\hline p-value & & 0.000 & 0.542 & 0.012 & 0.008 \\
\hline $\begin{array}{c}\text { OLS with } \\
\text { Clustered S.E. }\end{array}$ & & $\Delta P^{\min }$ & & $\Delta P^{\max }$ & \\
\hline Hotel Restaurant & & YES & $\mathrm{NO}$ & YES & $\mathrm{NO}$ \\
\hline diff before & (a) & -0.111 & 0.001 & -0.166 & -0.009 \\
\hline diff after & (b) & 0.224 & 0.030 & 0.103 & 0.055 \\
\hline $\begin{array}{c}\text { diff in diff } \\
\text { t-test }\end{array}$ & $(b)-(a)$ & 0.335 & 0.029 & 0.269 & 0.064 \\
\hline$(b)-(a)=0$ & & $2.19^{*}$ & 0.99 & $2.16^{*}$ & $2.46^{*}$ \\
\hline $\mathrm{p}$-value & & 0.029 & 0.321 & 0.031 & 0.014 \\
\hline
\end{tabular}

Notes: The model estimated is:

$$
\begin{array}{r}
\Delta P=\delta_{0}+\delta_{1} D_{N E}+\left(\delta_{2} H O T E L+\delta_{3} H O T E L \times D_{N E}\right) D_{00-01}+ \\
+\left(\delta_{4}+\delta_{5} D_{N E}+\delta_{6} H O T E L+\delta_{7} H O T E L \times D_{N E}\right) D_{01-02}+ \\
+\left(\delta_{8}+\delta_{9} D_{N E}+\delta_{10} H O T E L+\delta_{11} H O T E L \times D_{N E}\right) D_{02-03}+ \\
+\delta_{12} U P G R A D E+\delta_{13} D O W N G R A D E
\end{array}
$$

where HOTEL is equal to one (zero) if the restaurant is (is not) a hotel restaurant. Diff before is the price change for euro restaurants minus the price change for non-euro restaurants in period 2000-2001. Diff after is the price change for euro restaurants minus the price change for non-euro restaurants in period 2002-2003. When HOTEL $=1$, diff before is $-\left(\delta_{1}+\delta_{3}\right)$, diff after is $-\left(\delta_{1}+\delta_{11}+\delta_{9}\right)$. When HOTEL $=0$, diff before is $-\delta_{1}$, diff after is $-\left(\delta_{1}+\delta_{9}\right)$. $*=5 \%$ significant ${ }^{* *}=1 \%$ significant. ${ }^{* * *}=0.1 \%$ significant. 
TABLE 10: Percentage change in nights spent in tourist accommodations 20022000

\begin{tabular}{cccc}
\hline Country & Residents & Non residents & Overall \\
\hline Denmark & 0.069 & -0.043 & 0.020 \\
Sweden & 0.063 & 0.129 & 0.078 \\
UK & -0.049 & 0.051 & -0.023 \\
Italy & 0.013 & 0.041 & 0.024 \\
France & 0.008 & 0.062 & 0.017 \\
Germany & -0.019 & -0.048 & -0.023 \\
\hline
\end{tabular}

Notes: The table reports the percentage changes in nights spent in tourist accommodations by residents and non-residents for the countries included in the estimates (Source: Eurostat). 
Fig. 1 Differences in Cumulative Distribution Functions: Minimum Price

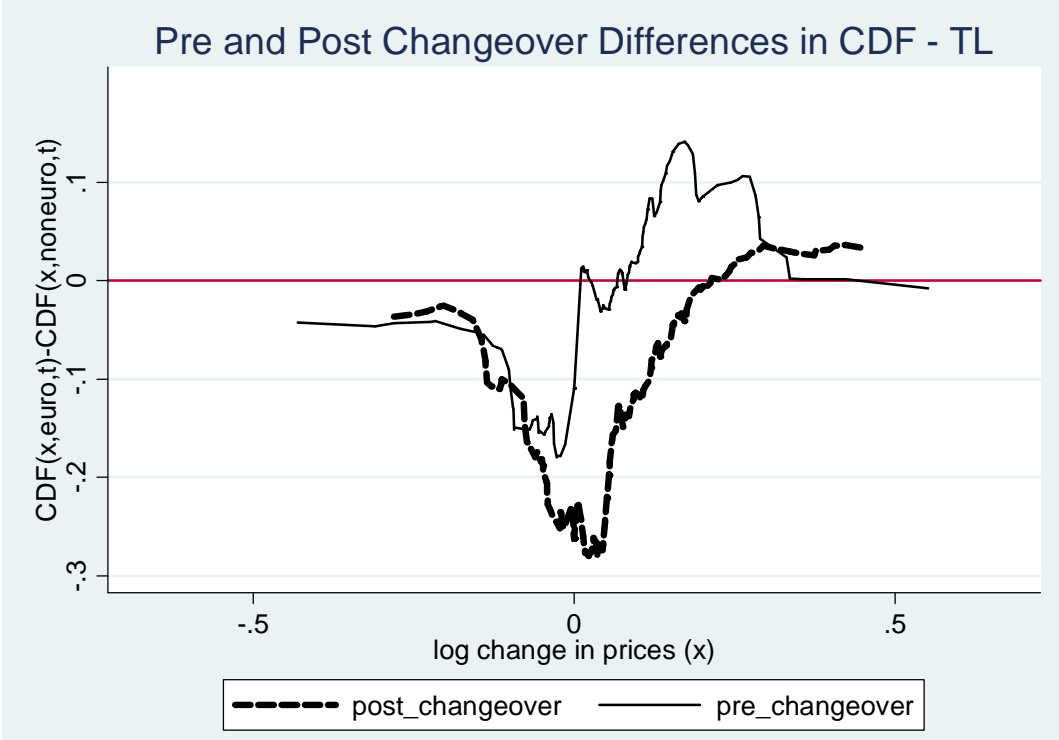

Pre and Post Changeover Differences in CDF - LL

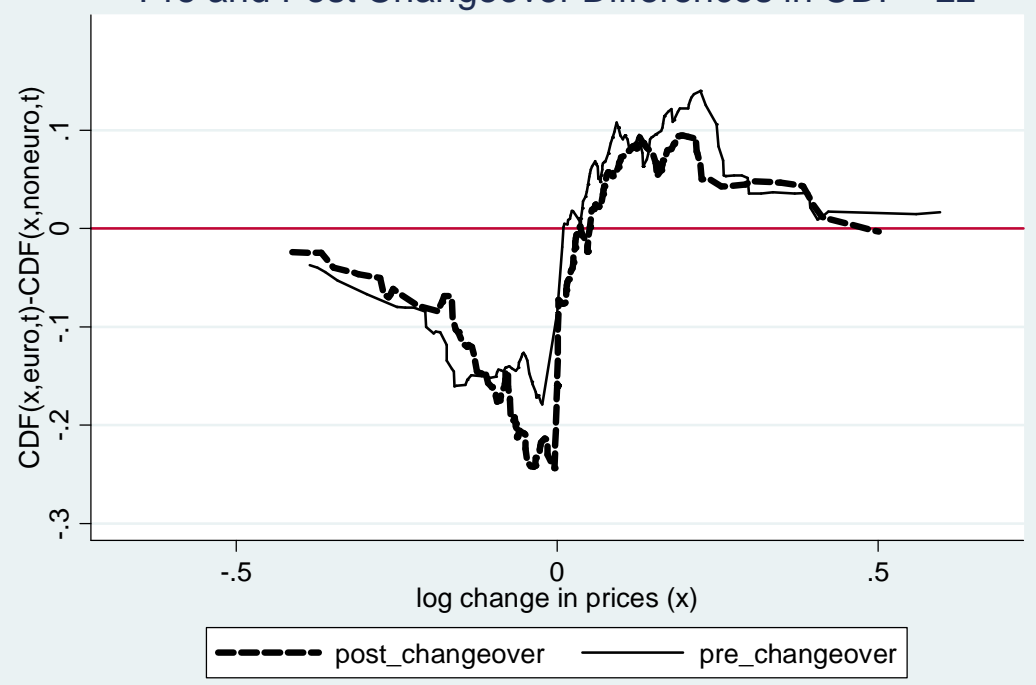

Pre and Post Changeover Differences in CDF - PL

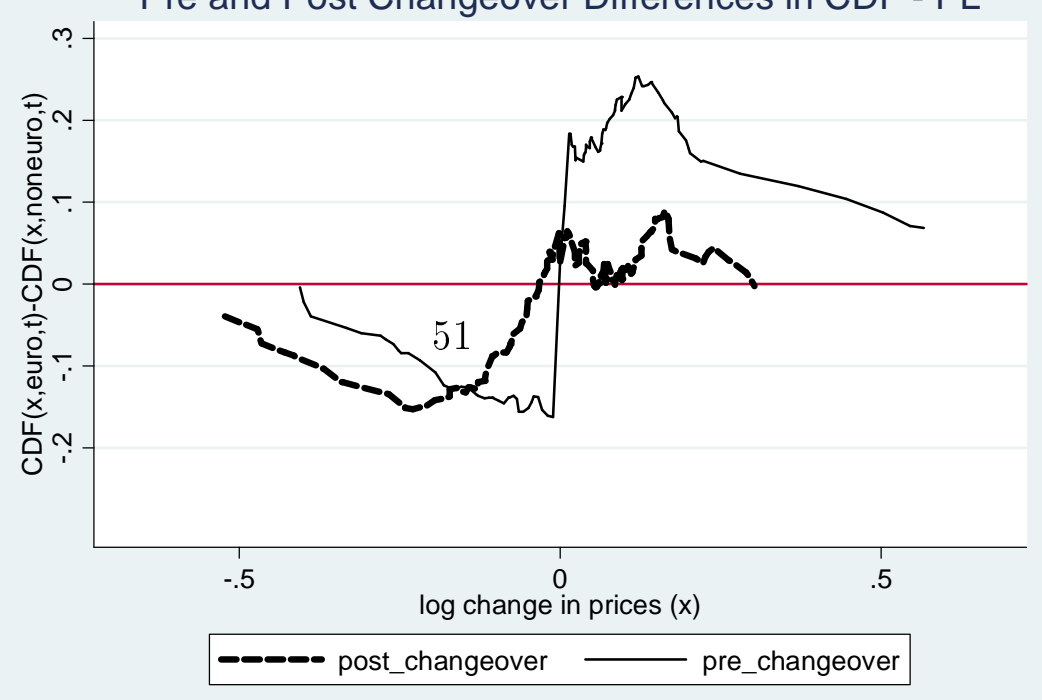


Fig. 2 Differences in Cumulative Distribution Functions: Maximum Price

Pre and Post Changeover Differences in CDF - TL

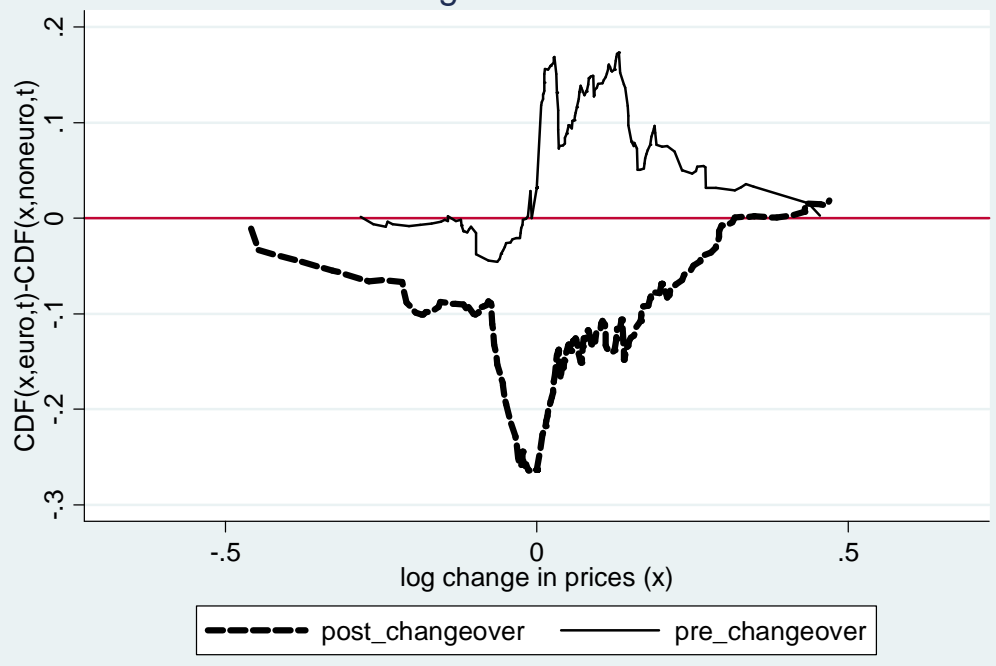

Pre and Post Changeover Differences in CDF - LL

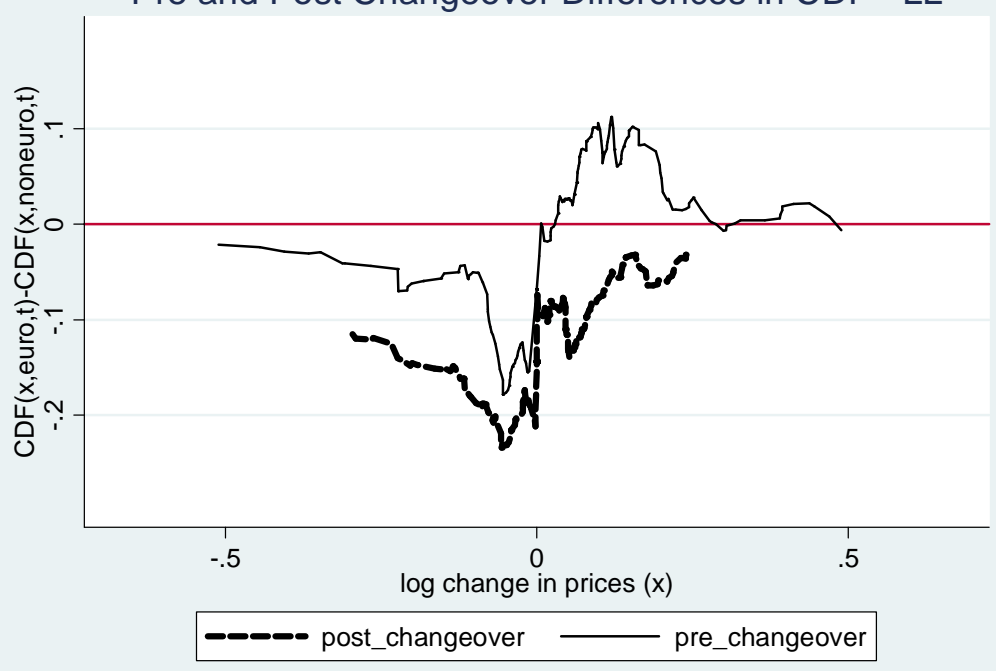

Pre and Post Changeover Differences in CDF - PL

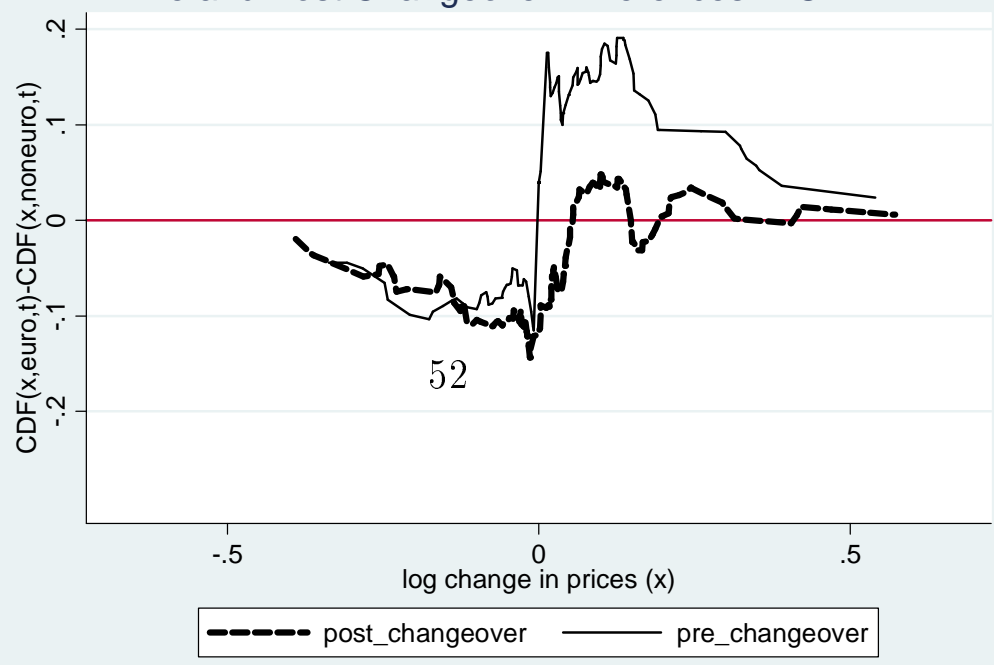


Fig.3 Cumulative Functions: Difference in Difference

Minimum Price

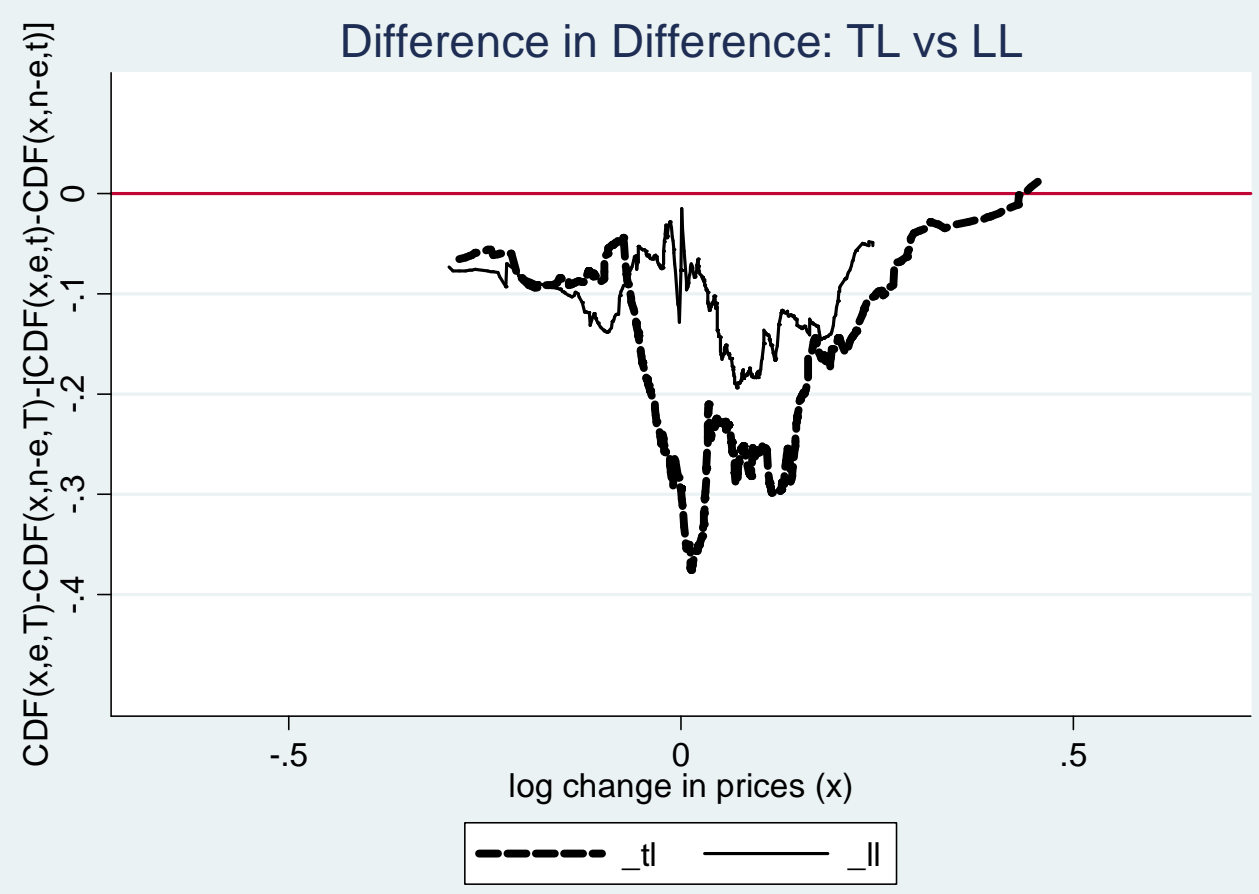

Maximum Price

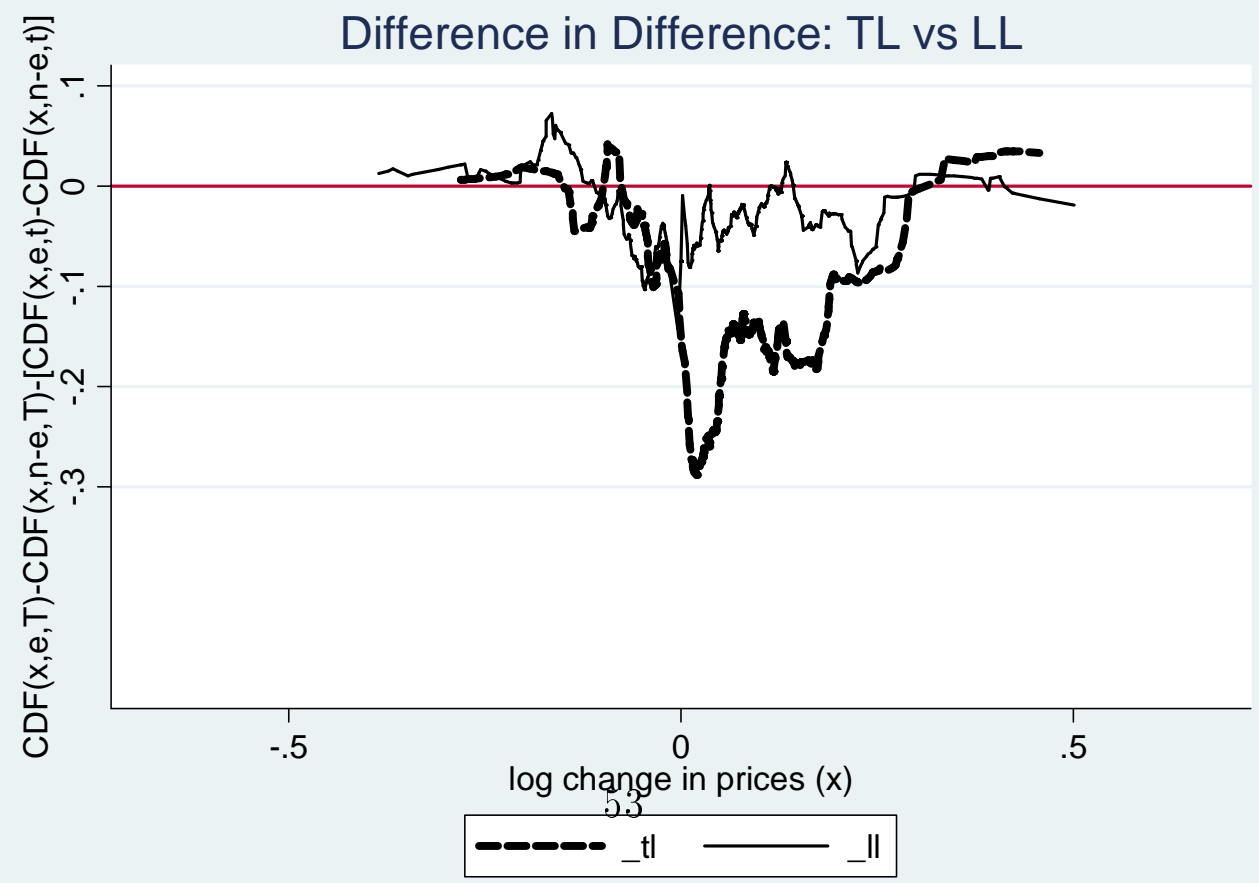

